\title{
Rodent versions of the lowa gambling task: opportunities and challenges for the understanding of decision-making
}

\section{Leonie de Visser ${ }^{1}{ }^{\dagger}$, Judith R. Homberg ${ }^{2 \dagger}$, Manuela Mitsogiannis ${ }^{3}$, Fiona D. Zeeb ${ }^{4}$, Marion Rivalan ${ }^{5}$, Aurélie Fitoussi ${ }^{5}$, Vasco Galhardo ${ }^{6}$, Ruud van den Bos ${ }^{3}$, Catherine A. Winstanley ${ }^{4}$ and Françoise Dellu-Hagedorn ${ }^{5}$}

\author{
Department of Neuroscience and Pharmacology, Rudolf Magnus Institute of Neuroscience, University Medical Centre, Utrecht, Netherlands \\ 2 Donders Institute for Brain, Cognition, and Behaviour, Radboud University Nijmegen Medical Centre, Nijmegen, Netherlands \\ ${ }^{3}$ Division of Behavioural Neuroscience, Department of Animals in Science and Society, Utrecht University, Utrecht, Netherlands \\ ${ }^{4}$ Department of Psychology, University of British Columbia, Vancouver, BC, Canada \\ ${ }^{5}$ CNRS, UMR 5287, Aquitaine Institute of Cognitive and Integrative Neuroscience, University of Bordeaux, Bordeaux, France \\ ${ }_{6}^{6}$ Departamento de Biologia Experimental, Instituto de Biologia Molecular e Celular, Universidade do Porto, Porto, Portugal
}

Edited by:

Tobias Kalenscher, Heinrich-Heine

University Duesseldorf, Germany

Reviewed by:

Leontien Diergaarde, VU Medical

Center, Netherlands

Daniel Bryden, University of Maryland

College Park, USA

\section{*Correspondence:}

Leonie de Visser, Department of

Neuroscience and Pharmacology,

Rudolf Magnus Institute of

Neuroscience, University Medical

Center Utrecht, Universiteitsweg 100,

3584 CG Utrecht, Netherlands.

e-mail: I.devisser-10@umcutrecht.nl

${ }^{\dagger}$ Leonie de Visser and Judith $R$.

Homberg have contributed equally to this work.
Impaired decision-making is a core problem in several psychiatric disorders including attention-deficit/hyperactivity disorder, schizophrenia, obsessive-compulsive disorder, mania, drug addiction, eating disorders, and substance abuse as well as in chronic pain. To ensure progress in the understanding of the neuropathophysiology of these disorders, animal models with good construct and predictive validity are indispensable. Many human studies aimed at measuring decision-making capacities use the lowa gambling task (IGT), a task designed to model everyday life choices through a conflict between immediate gratification and long-term outcomes. Recently, new rodent models based on the same principle have been developed to investigate the neurobiological mechanisms underlying IGT-like decision-making on behavioral, neural, and pharmacological levels. The comparative strengths, as well as the similarities and differences between these paradigms are discussed. The contribution of these models to elucidate the neurobehavioral factors that lead to poor decision-making and to the development of better treatments for psychiatric illness is considered, along with important future directions and potential limitations.

Keywords: lowa gambling task, animal model, validity, dopamine, serotonin, neurobiology

\section{INTRODUCTION}

Decision-making plays a pivotal role in daily life. Impairment in this process, as observed in several psychiatric disorders, results in an inability to make profitable long-term decisions that incorporate expectations of future outcomes (for review, see Dunn et al., 2006). Impaired decision-making is recognized as a core problem in disorders like substance abuse (Grant et al., 2000; Bechara, 2001; Bechara and Damasio, 2002; Bechara et al., 2002; Ernst et al., 2003; Bechara and Martin, 2004; Whitlow et al., 2004; Dom et al., 2006; Hanson et al., 2008), pathological gambling (Cavedini et al., 2002b; Brand et al., 2005; Goudriaan et al., 2005, 2006), schizophrenia (Bark et al., 2005; Shurman et al., 2005; Kester et al., 2006; Lee et al., 2007b; Sevy et al., 2007), obsessive-compulsive disorder (OCD; Lawrence et al., 2006; da Rocha et al., 2008; Cavedini et al., 2010; Starcke et al., 2010), eating disorders (Cavedini et al., 2004; Tchanturia et al., 2007; Liao et al., 2009; Brogan et al., 2010), attention-deficit hyperactivity disorder (ADHD; Toplak et al., 2005; Garon et al., 2006; Malloy-Diniz et al., 2007; Luman et al., 2008) chronic pain (Apkarian et al., 2004; Verdejo-García et al., 2009), and Parkinson's disease (Brand et al., 2004). Therefore, understanding the mechanisms underlying poor decision-making is key to successful treatment of neurological and psychiatric disorders. This is why decision-making is studied intensively by disciplines ranging from neuroscience, cognitive and social psychology, to experimental and behavioral economics (Kahneman and Tversky, 1979) leading to the recent interdisciplinary field of neuroeconomics that combines all these disciplines (Glimcher et al., 2009).

The Iowa gambling task (IGT) is the most commonly used task to assess decision-making performance in a clinical setting (Bechara et al., 1994, 1999). The IGT is particularly interesting because it mimics the complexity of the choices that we are confronted with in everyday life. Its design incorporates the unpredictability of the consequences of a choice, the need to weigh shortand long-term gains and losses, and the necessity to exert behavioral control to maximize gains in the long-term. Successful performance requires the integration of several executive functions: individuals must demonstrate flexibility in planning to account for various outcomes, constantly monitor incoming information, evaluate the risk-reward ratio for various decision-making options, and refrain from choosing the options that are immediately more rewarding. For these reasons, successful performance requires the integration of several executive functions. The IGT was originally developed to assess the specific cognitive impairments of prefrontal cortex-damaged individuals (Bechara et al., 1994), but impaired performance has subsequently been observed following damage to other brain regions such as the amygdala, insula, and more controversially, the dorsolateral prefrontal cortex (dlPFC) (Bechara et al., 1998, 1999; Manes et al., 2002; Clark et al., 2003; Fellows and Farah, 2005), as well as in a range of psychiatric 
populations (see above). Several (psychiatric) conditions induce various kinds of deficits in the IGT, like disadvantageous deck preference (schizophrenia, OCD, pathological gambling, substance abusing individuals, psychopathic individuals, ADHD, chronic pain) with preference for infrequent punishments (ADHD, schizophrenia); no preference [anxiety, (Miu et al., 2008; de Visser et al., 2010)]; slower learning (mania, substance-dependent individuals) or deficits in reversal learning (schizophrenia; for review, see Dunn et al., 2006). The effects of genetic polymorphisms, pharmacological treatments, as well as functional neuroimaging data, have significantly expanded our knowledge of the neural substrates underlying decision-making, and how their functions are compromised in individuals with decision-making deficits.

Interest is growing in the development of rodent models of decision-making for several practical reasons (see also Potenza, 2009). First, such models are indispensable for the dissection of precise mechanisms involved in decision-making, such as the role of specific brain regions and circuits, modulation by the monoaminergic systems, and neurodevelopmental events. Second, rodents are particularly suitable for screening and identifying risk or protective factors for poor decision-making. Rodent studies are not subject to the same time constraints associated with longitudinal studies in human populations and easily allow the study of inter-individual differences in behavioral and cognitive capacities (Rivalan et al., 2009b). Third, animal models are particularly valuable since environmental conditions as well as genetic variation can be carefully controlled. As such, animal models of the IGT have recently been developed (van den Bos et al., 2006; Pais-Vieira et al., 2007; Rivalan et al., 2009a; Zeeb et al., 2009). These models are largely complementary, yet have distinct strengths. Here we aim at describing the current state of these novel models with respect to face, predictive, and construct validities. We will present recent findings that demonstrate their potential to investigate the neuropsychobiological mechanisms of decision-making as well as directions for future research.

\section{THE IOWA GAMBLING TASK TASK CHARACTERISTICS}

The IGT requires individuals to choose cards, one by one, between four different decks to earn money. Two decks are equally advantageous in the long run because cards chosen from these decks provide immediate moderate monetary gains but also moderate or low losses according to two different probability schedules. Two decks are equally disadvantageous in the long run because even though immediate gains are higher, the unpredictable losses are also higher, according to two different probability schedules (Figure 1). Thus, a conflict is induced between immediate high rewards and long-term gains. Participants are not provided with any information as to which choice is optimal, but they are instructed to try to maximize their gains as much as possible by freely choosing cards from each deck, and have the ability to switch between decks at any time (Bechara et al., 1999). Subjects therefore need to discover the task contingencies by trial and error. This sets the IGT apart from tasks that overtly signal the odds of winning such as the Cambridge Gambling Task (Clark et al., 2003).

When performing the IGT, healthy human subjects usually display a shift from primarily explorative behavior at the beginning of the task, during which they sample from all decks, toward a more exploitative strategy involving substantially more choices of the advantageous options associated with the best long-term outcome (Bechara et al., 1994, 1999; Brand et al., 2007b). Thus, decisionmaking is first made under ambiguous conditions, in that the subjects do not know what the reinforcement contingencies are. Following repeated sampling from the decks, it can be assumed that subjects are more aware of the chances of winning or losing associated with each deck, and therefore risky decision-making can take place (Stoltenberg and Vandever, 2010, but see Fellows and Farah, 2005).

Patients suffering from psychiatric disorders in which decisionmaking is compromised typically persevere in their choice of the disadvantageous options that yield immediate large rewards, despite larger losses in the long-term. Interestingly, a subset of healthy individuals also makes poor decisions in the IGT, suggesting a continuum between normal and pathological conditions (Brown and Barlow, 2005). Therefore, it can be hypothesized that poor decision-making in clinical and non-clinical populations shares common neuropsychological characteristics. As such, identification of these markers could improve our understanding of the transition from a healthy vulnerable state to psychiatric conditions.

\section{NEURAL SUBSTRATES}

Studies using brain-lesioned patients and imaging techniques have provided consistent evidence that decision-making depends on

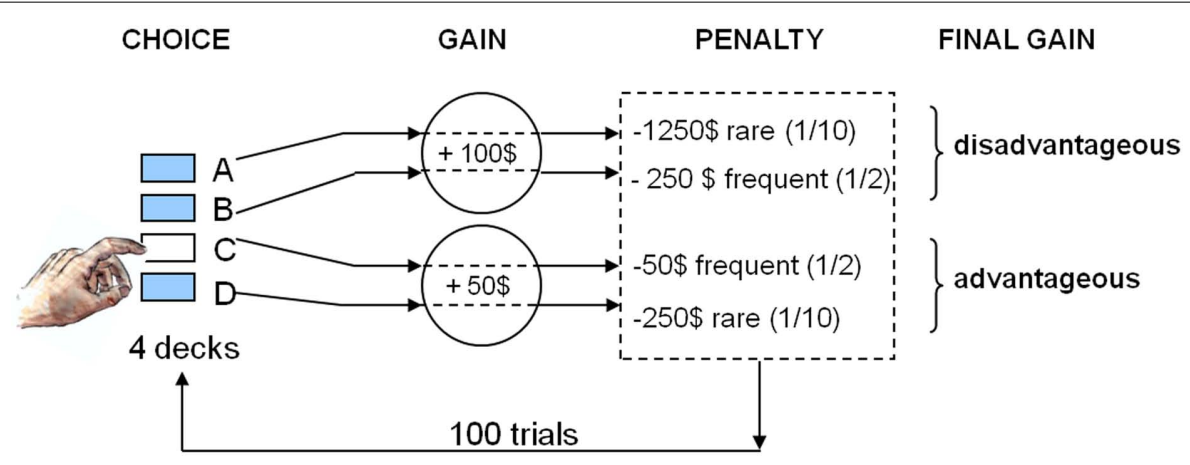

FIGURE 1 | Schematic set-up of the lowa gambling task. 
the integrity of, and functional connectivity between, many brain areas. The main structures are the amygdala, the insula, the striatum (STR), and several frontal cortical regions, including ventromedial prefrontal cortex (vmPFC), orbitofrontal cortex (OFC), the anterior cingulate cortex (ACC), and dlPFC (Bechara et al., 1999; Manes et al., 2002; Bolla et al., 2004; Tucker et al., 2004; Fellows and Farah, 2005; Hsu et al., 2005; Brand et al., 2007a).

The somatic marker hypothesis proposes that emotion-based biasing signals arising from the body are integrated in higher brain regions, notably the vmPFC, the amygdala, the insula, and the somatosensory cortex to regulate complex decision-making (Bechara et al., 1997; Dunn et al., 2006). This hypothesis is based on the fact that successful IGT performance is related to the development of somatic marker signals, as indexed by the magnitude of anticipatory skin conductance responses, before any conscious knowledge of the adapted choices (Bechara et al., 1994, 1997). These signals serve as an indicator of the value presented. If they are ineffective, like in vmPFC lesioned people, solving the task is no more possible. Within the vmPFC, the OFC is involved in the treatment, evaluation and filtering of perceptual, social, and emotional information (Elliott et al., 2000). This region is strongly interconnected with areas within the limbic system, particularly the basolateral amygdala (BLA), and receives prominent inputs from sensory association cortices. This pattern of connectivity suggests that the OFC plays a role in integrating potentially salient information about environmental contingencies (Ongur and Price, 2000), and uses this information to assign a value to a reward and signal outcome expectancies which can thus influence action selection (Schoenbaum et al., 2003; Rolls and Grabenhorst, 2008; Mainen and Kepecs, 2009; Takahashi et al., 2009). Thus, the OFC allows the representation of the reinforcing consequences of a choice to adapt goal-directed behaviors (Mainen and Kepecs, 2009) and modulates this value according to the contingency changes (Schoenbaum et al., 1998; Murray et al., 2007; Hayton and Olmstead, 2009).

The ACC is a converging area for cognitive and motor commands (Paus et al., 1993) that monitors and detects the presence of conflicts related to actions (Magno et al., 2006; Oliveira et al., 2007), whereas the dlPFC, tightly connected with ACC and OFC (Barbas, 2000), engages a top-down process required to monitor and implement change (Hyafil et al., 2009). The ACC signals error-likelihood (Sallet et al., 2007) and has a key role in choosing and updating appropriate actions when the environment is uncertain or dynamic (Kennerley et al., 2006; Quilodran et al., 2008), and in combining information about the costs and benefits associated with alternative actions (Rudebeck et al., 2006). This update is made in combination with the dlPFC, which is critically involved in the temporary maintenance of recently acquired information (Lee et al., 2007a), and in the detection of action-outcome contingencies (Balleine and O'Doherty, 2010), a major aspect of associative learning that allows the elaboration of goal-directed responding.

It has been suggested that the exploration and exploitation phases of the IGT involve different brain areas (van den Bos et al., 2007). The exploration phase may be mediated by the amygdala and ventral STR and their projections to the OFC (Bechara et al., 1999; Knutson et al., 2001). When the task progresses and a preference for the advantageous decks is emerging, the ACC,
dlPFC, and dorsal STR may be recruited to engage in cognitive control of the once established choice in order to maintain and exploit this strategy to secure long-term payoff (Bush et al., 2000; Ernst et al., 2002; McClure et al., 2004; Ridderinkhof et al., 2004; Pezawas et al., 2005). However, large inter-individual differences in brain areas recruitment according to performances in the IGT, certainly occurs. Animal models of the IGT are uniquely placed to assess the validity of these theories, as brain imaging studies or lesions to particular areas can be selectively implemented at different stages of training, thereby preferentially targeting either the exploitation or exploration phases (de Visser et al., 2011b; Rivalan et al., 2011; Zeeb and Winstanley, 2011).

\section{NEUROMODULATORS}

The dopaminergic and serotonergic systems, known to facilitate functional connectivity between the limbic and cortical regions, are important candidates for modulating decisionmaking. Changes in the functioning of these neurotransmitter systems have been associated with pathological gambling, the psychiatric disorder perhaps best classified as a disorder of excessive risk-taking behavior and maladaptive decision-making (Shinohara et al., 1999; Seedat et al., 2000; Meyer et al., 2004; Pallanti et al., 2006; Zack and Poulos, 2007; Marazziti et al., 2008; Pattij and Vanderschuren, 2008). Furthermore, several polymorphisms in serotonergic and dopaminergic genes have been identified that affect frontal and sub-cortical brain function and personality traits (e.g., neuroticism, harm avoidance, persistence, and noveltyseeking), which play a central role in decision-making (e.g., Ha et al., 2009; Krugel et al., 2009; Homberg and Lesch, 2010; Juhasz et al., 2010; Paloyelis et al., 2010).

\section{Serotonergic system and decision-making in the IGT}

Several lines of evidence suggest that there is an inverse relationship between serotonin levels and impulsivity (Linnoila et al., 1983; Soubrie, 1986), a trait that may affect decision-making. For instance, users of the serotonergic neurotoxic drug MDMA show poorer IGT performance and elevated self-reported impulsivity relative to controls (Hanson et al., 2008). Additionally, in OCD patients, chronic treatment with risperidone, a mixed $5-\mathrm{HT}_{2 \mathrm{~A}}-\mathrm{D}_{2}$ receptor antagonist, was found to improve overall IGT performance in patients exhibiting initially worse performance (Cavedini et al., 2002a).

Gene variants related to serotonin function have been associated with deficits in decision-making during the IGT. In particular, variants in the ACGCCG haplotype of the tryptophan hydroxylase (TPH)-1 gene (Maurex et al., 2009), polymorphisms in the serotonin-related TPH-2 and monoamine oxidase A (MAOA) genes (Jollant et al., 2007) and in the common serotonin transporter (SERT) promoter (Lesch et al., 1996) have been linked to poor IGT performance. Furthermore, patients with major depression or OCD carrying the low activity (short; s) allelic variant of the serotonin-transporter-linked polymorphic region (5-HTTLPR) showed increased choice of the disadvantageous options in the IGT (Must et al., 2007; da Rocha et al., 2008; He et al., 2010; Stoltenberg and Vandever, 2010). Comparable results were obtained in healthy female subjects (Homberg et al., 2008; van den Bos et al., 2009b, but see Lage et al., 2011). However, studies based on male volunteers 
have yielded conflicting results (He et al., 2010; Stoltenberg and Vandever, 2010; Lage et al., 2011). Because the SERT is responsible for serotonin reuptake into the presynaptic nerve terminal, the s-allele is hypothesized to be associated with increased extracellular serotonin levels (Lesch et al., 1996; Kalueff et al., 2009). Of interest, the s-allele, compared to the l-allele, is associated with amygdala hyperactivity in response to fearful stimuli and at rest (Hariri et al., 2002; Canli et al., 2006). This hyperactivation correlates with reduced volume of the ACC, as well as a functional and anatomical uncoupling between the ACC and amygdala (Pezawas et al., 2005; Pacheco et al., 2009) and hyperactivity of the vmPFC (Heinz et al., 2005). One speculation is that people carrying the 5-HTTLPR s-allele are hypervigilant, which is advantageous when environmental stimuli are controllable and manageable. Indeed, in a risky decision-making task with choice probability outcomes made explicitly s/s subjects chose more advantageously due to increased risk adversity (Kuhnen and Chiao, 2009). Conversely, under conditions in which stimuli are uncertain, such as during the IGT, s-allele carriers engage in maladaptive behavior (Homberg and Lesch, 2010). Overall, these data indicate that serotonin signaling can negatively affect decision-making on the IGT, with possible sex-dependent effects during the explorative phase of the task.

\section{Dopaminergic system and decision-making in the IGT}

Changes in the dopaminergic system have likewise been shown to modulate IGT performance. As previously noted, poor IGT performance has been observed in several pathologies related to dopamine dysfunction, such as schizophrenia, Parkinson's disease, drug addiction, and pathological gambling (Comings et al., 1996; Rogers et al., 1999; Mimura et al., 2006). Dopamine is critically involved in associative learning (Schultz, 2002) time perception (Meck, 2006) and signaling within the reward system (Di Chiara and Bassareo, 2007), all of which are fundamental processes required for decision-making. Consequently, it is not surprising that reduction of dopaminergic levels impairs decision-making in healthy individuals. Acute administration of a branchedchain amino acids (BCAA) mixture lowers the plasma ratio of dopamine's precursor amino acids and decreases dopaminergic activity (Harmer et al., 2001; Gijsman et al., 2002). This treatment also orientates healthy male participants toward disadvantageous decks in later trials as their dopamine levels reduce, thus indicating a fundamental function of dopaminergic signaling in advantageously guiding decision-making during the IGT (Sevy et al., 2006). This impairment could be related to reduced perception of probability and time, given that attention was shifted toward more recent events compared to more distant events (van den Bos et al., 2007). PET imaging data also indicate a positive correlation between dopamine release in the ventral striatum and IGT performance in healthy male participants (Linnet et al., 2010), yet a negative correlation in problem gamblers (Linnet et al., 2011). However, the $\mathrm{D}_{2}$ antagonist haloperidol increased the drive to play slot machines in pathological gamblers, but not in healthy controls (Zack and Poulos, 2007).

Two genetic factors mediating dopamine signaling, namely the catechol-O-methyltransferase (COMT) enzyme and the $\mathrm{D}_{4}$ dopamine receptor $\left(\mathrm{DRD}_{4}\right)$, are also related to IGT performance. The rs $4818 \mathrm{C} / \mathrm{G}$ polymorphism of the COMT gene, which results in an 18 -fold divergence of enzymatic activity between the high activity variant ( $\mathrm{G}$ allele) and low activity variant (C allele; Nackley et al., 2006), has been shown to significantly affect performance in the IGT. In particular, male subjects homozygous for the high activity variant performed better than those carrying the low activity variant (Roussos et al., 2008). In a financial risk decisionmaking task in which subjects were informed on the payoff of choice options carriers of the 7-repeat allele of $\mathrm{DRD}_{4}$ were significantly more risk seeking relative to those individuals without the 7-repeat allele (Kuhnen and Chiao, 2009), indicating that the 7R allele is associated with novelty-seeking regardless of choice conditions (uncertain or certain). Another COMT gene polymorphism, Val158Met, is associated with IGT performance in healthy females. The Met/Met variant, related to lower COMT activity and higher constitutive dopamine prefrontal cortical levels, lead to poorer performances compared to Val/Val (Lotta et al., 1995; Mannisto and Kaakkola, 1999; Chen et al., 2004; van den Bos et al., 2009b); but see (Kang et al., 2010). Interestingly, carriers of both the Met/Met and 5-HTTLPR-s/s genotypes displayed the worst IGT performance among all possible COMT and 5-HTTLPR genotype combinations (van den Bos et al., 2009b), indicating that the dopaminergic and serotonergic systems may interact in the modulation of IGT choice behavior.

Regarding the variable number of tandem repeat (VNTR) polymorphism in the $\mathrm{DRD}_{4}$ gene, healthy male carriers of the seven repeats (7R) allele of this gene choose significantly more cards from disadvantageous decks in the IGT compared to participants exhibiting the 4R allele (Roussos et al., 2009). This 7R allele is associated with lower transcriptional/translational levels and diminished in vivo receptor responsivity compared to the four repeats (4R) allele (Hutchison et al., 2003; Hamarman et al., 2004; McGough, 2005; Brody et al., 2006; Ebstein, 2006).

Collectively, these data suggest that dopamine, possibly in interaction with serotonin, can modulate decision-making as measured in the IGT. Serotonin may be inversely associated with IGT performance, whereas directional consensus for dopamine is not yet fully clear. Pathological gamblers and healthy controls appear to react differently to dopaminergic manipulations, and may also differ in their baseline and gambling-induced changes in DA release. However, our understanding of the monoaminergic modulation of IGT performance is still limited, and consequently, pharmacogenetic treatment of decision-making deficits in patients is currently a distant goal.

\section{MODELING THE IGT IN RODENTS}

It is comparatively easy to perform pharmacological, genetic, and environmental manipulations in mice and rats. Hence, rodent IGT models $(R G T s)$ can make a crucial contribution to scientific and medical advances in the field of decision-making. For this purpose, paradigms which capture the essence of the IGT have been developed for use in rodents in order to establish animal models of human decision-making with high face and construct validities.

The IGT (Bechara et al., 1994) has several key features that had to be reproduced. As reviewed below, four different types of rodent IGT models have been designed that incorporate several of these key features (Table 1). These models differ both in the equipment used (mazes vs. operant chambers), the task duration (from a single session to several daily sessions), the learning of task contingencies and the ratio between advantageous vs. disadvantageous 
Table 1 | Main features of the human and rodent gambling tasks.

\begin{tabular}{|c|c|c|c|c|c|}
\hline Task features & IGT & $\mathrm{RGT}_{\text {reward or quinine }}$ & $\mathrm{RGT}_{\text {reward probabilities }}$ & $\mathbf{R G T}_{\text {one session reward and time-out }}$ & $\mathbf{R G T}_{\text {reward or time-out }}$ \\
\hline Original references & $\begin{array}{l}\text { Bechara et al. } \\
\text { (1994) }\end{array}$ & $\begin{array}{l}\text { van den Bos et al. } \\
\text { (2006) }\end{array}$ & $\begin{array}{l}\text { Pais-Vieira et al. } \\
\text { (2007) }\end{array}$ & Rivalan et al. (2009) & Zeeb et al. (2009) \\
\hline Apparatus & $\begin{array}{l}\text { Computerized } \\
\text { card game }\end{array}$ & $\begin{array}{l}\text { Manually operated } \\
\text { maze }\end{array}$ & $\begin{array}{l}\text { Manually/automated } \\
\text { arena }\end{array}$ & Automated operant chamber & $\begin{array}{l}\text { Automated operant } \\
\text { chamber }\end{array}$ \\
\hline No. of choice options & 4 & 4 & 2 & 4 & 4 \\
\hline Reward & Monetary gain & Sucrose pellets & Sucrose pellets & Palatable food pellets & Sucrose pellets \\
\hline Reward occurence & Each trial & $\begin{array}{l}\text { Alternate with } \\
\text { punishment }\end{array}$ & $\begin{array}{l}\text { Alternate with } \\
\text { punishment }\end{array}$ & Each trial & Alternate with punishment \\
\hline Punishment & Monetary loss & Quinine pellets & No reward & Time-outs & Time-outs \\
\hline $\begin{array}{l}\text { Conflict immediate } \\
\text { rewards }\end{array}$ & $\begin{array}{l}100(A \text { and } B) \\
\text { vs. } 50(C \text { and } D)\end{array}$ & $3(\mathrm{~A})$ vs. $1(\mathrm{~B})$ & $3(A)$ vs. $1(B)$ & $2(\mathrm{~A}$ and $\mathrm{B})$ vs. $1(\mathrm{C}$ and $\mathrm{D})$ & $\begin{array}{l}\text { 3;4 ( } A \text { and } B \text { ) vs. 1;2 ( } C \text { and } \\
\text { D) }\end{array}$ \\
\hline $\begin{array}{l}\text { Conflict long-term } \\
\text { payoff }\end{array}$ & $\begin{array}{l}\text { Per } 10 \text { cards } \\
-250 \text { vs. }+250\end{array}$ & $\begin{array}{l}\text { Per } 10 \text { trials } 3 \text { vs. } 8 \\
\text { pellets ratio }=2.7\end{array}$ & $\begin{array}{l}\text { Per } 10 \text { trials } 9 \text { vs. } 8 \\
\text { pellets ratio }=0.9\end{array}$ & $\begin{array}{l}\text { Total test: } 60 \text { vs. } 300 \text { pellets } \\
\text { ratio }=5\end{array}$ & $\begin{array}{l}\text { Total test: } 353 \text { vs. } 117 \\
\text { (average) ratio }=3\end{array}$ \\
\hline Task duration & $\begin{array}{l}\text { Single session } \\
\text { (100 trials) }\end{array}$ & $\begin{array}{l}10 \text { daily sessions } \\
(10-20 \text { trials })\end{array}$ & Single session & Single session (1 h) & $\begin{array}{l}25 \text { daily sessions for stabil- } \\
\text { ity (approximately } 100 \text { trials } \\
\text { per } 30 \text { min session) }\end{array}$ \\
\hline $\begin{array}{l}\text { Pre-training } \\
\text { procedure }\end{array}$ & None & 10-min habituation & 20-25 days & $5-7$ days & $\begin{array}{l}\text { 10-15 days incl. } 7 \text { forced- } \\
\text { choice sessions }\end{array}$ \\
\hline $\begin{array}{l}\text { Prior knowledge of } \\
\text { contingencies }\end{array}$ & No & No & No & No & Yes \\
\hline Motivational aspects & $\mathrm{n} / \mathrm{a}$ & $90-95 \%$ of FFW & $80 \%$ of $\mathrm{FFW}$ & $95 \%$ of $\mathrm{FFW}$ & $85 \%$ of $\mathrm{FFW}$ \\
\hline
\end{tabular}

Values for the conflict long-term payoff are hypothetical calculations for RGT and RGT (based on a fixed trial duration of 9 or $5 s$ respectively). FFW, free-feeding weight.

options. The way in which loss is signaled also differs: making sugar pellets aversive through the addition of the bitter-tasting substance quinine (van den Bos et al., 2006; rats and mice), simple non-reward (Pais-Vieira et al., 2007; rats), or the delivery of timeout periods on loss trials which minimize the number of pellets the animals can earn (Rivalan et al., 2009a; rats, Zeeb et al., 2009; rats, Young et al., 2011; mice).

\section{CONFLICT BETWEEN PROBABILITIES OF HIGH FOOD REWARD VS. QUININE: A FOUR-ARM BOX MAZE MODEL (RGT REWARD OR QUININE)}

The first experimental protocol aiming to reproduce the characteristics of the IGT in rodents was developed by van den Bos et al. (2006). This task measures the choice between four goal arms, two of them containing either food rewards or punishments per choice. High amount of rewards is combined with the incurrence of a high amount of punishment in the disadvantageous arm, as opposed to the advantageous one. Uncertainty is given by varying the sequence of sugar or quinine pellet presentation. The apparatus (Figure 2) consists of a box divided in three different areas: a starting zone, a choice zone, and an arena divided in four parallel arms. The goal arms, labeled A, B, C, and $\mathrm{D}$, are provided with internal visual cues (symbols of different shapes and colors) to help animals in differentiating them during the task apart from the spatial location. They contain "monetary rewards" in the form of sugar pellets, or "monetary punishments" that are quinine-treated (bitter) sugar pellets. Before testing, animals are habituated to the sugar pellet taste and briefly allowed to explore the maze (10 min). Any animals which continue to eat the quinine-treated sugar pellets are removed from the experiment. Test trials are initiated by removing the slide door from the start box. The animal is allowed to freely explore the choice area. A choice for one of the arms is made when the animal has walked into the arm for at least one-third of the length of the arm. Once a choice is made, the arm is closed to prevent the animal from walking back without investigating the reward cup. During testing [ 10 trials a day for 12 days, but modifications of this schedule have been used (de Visser et al., 2011b)], the pre-arranged schedule of wins and losses associated with the arms are represented according to a pre-arranged random order of sugar and quinine pellets for each arm of the box. One "disadvantageous" and one "advantageous" arm are present. In the former case, the chance of obtaining high immediate rewards combined with the incurrence of a high net loss in the long run is reproduced by presenting three sugar pellets once every 10 choices and one quinine-treated pellet every other time. In the latter case, the possibility of receiving low immediate rewards but having a net gain over multiple choices is achieved by administering one sugar pellet eight times in 10 selections and one quinine-treated pellet every other time. The 


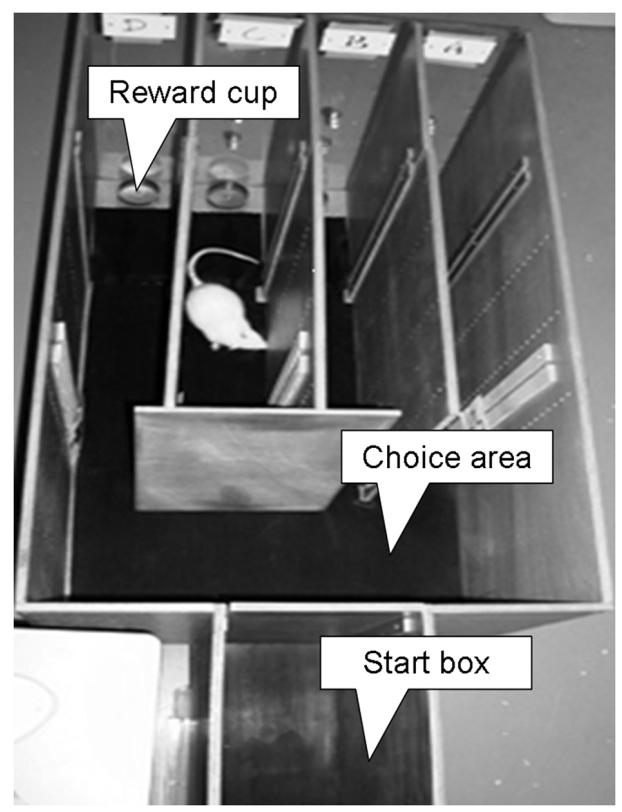

FIGURE 2 |The four-arm box maze model (RGT ): top view of the maze with start box, choice area, and four arms with reward cups. When an animal has made a choice for a particular arm, this arm is closed off with a slide to prevent the animal from returning to the choice area before investigation of the reward cup.

uncertainty of rewards and punishments per choice provided by the human task is maintained by varying the sequence of sugar or quinine pellet presentation between blocks of 10 trials in each arm. Consequently, the net gain ratio between advantageous and disadvantageous options is 2.67. The distribution of punishments is randomized per 10 trials and disadvantageous options are not "stacked" toward the end of the task (see Fellows and Farah, 2005). Control for non-specific exploration is assessed by entries into the two empty arms. A mouse version of the IGT has also been designed by van den Bos et al. (2006), using an eight-arm radial maze. This task presents main characteristics that similar to those of the rat gambling task as described above.

Recently, an operant version of $\mathrm{RGT}_{\text {reward or quinine has been }}$ developed using specially designed operant panels that are placed in the home cage of rats (Koot et al., 2009, 2010). Next to measuring decision-making, this task allows assessment of impulsivity (Koot et al., 2010) and is currently being further validated.

\section{PREFERENCE FOR HIGH VS. LOW PROBABILITIES TO GET SIMILAR AMOUNT OF REWARD: A TWO-LEVER OPERANT CHAMBER MODEL \\ (RGT REWARD PROBABILITIES)}

In 2007, a second rodent task that modeled some features of the IGT was established by Pais-Vieira et al. (2007). This task measures the preference for an infrequent high amount of food compared to a more frequent, lower amount of food, both options leading to an almost similar amount of total reward. Another task was recently established, based on the same principle (Roitman and Roitman, 2010), but with a lower level of unpredictability.

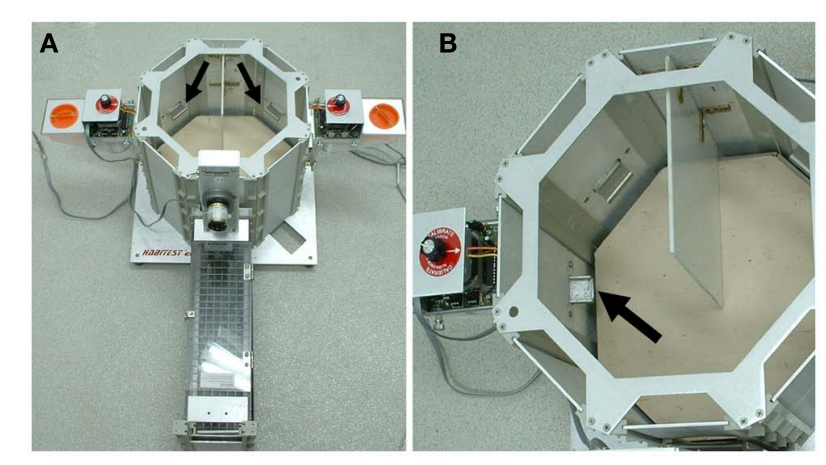

FIGURE 3 | The two-lever operant chamber model (RGT

(A) Octagonal arena connected to a starting corridor. Levels are indicated by the arrows. (B) The arena is divided in two sides by a central separator, each containing one lever and one food cup (indicated by an arrow) connected to an automated pellet dispenser.

The apparatus (Figure 3) consists of an octagonal arena connected to a starting corridor through a guillotine door. The arena is divided in a right and a left side by a central separator, and each half of the arena is provided with one food cup and one lever connected to an automated pellet dispenser. Training consists of two phases: first, animals undergo a series of sessions to get familiarized with the testing apparatus and to learn the association between lever presses and food delivery. Subsequently, rodents are subjected to five sessions of 30-90 trials in which the outcome values are identical for both sides of the arena (one food pellet in 8 out of every 10 consecutive presses). These sessions serve as a control for individual spatial bias: animals preferring one side of the arena in more than $70 \%$ of the trials in two of the five sessions are removed from the study. Each trial begins with the animal in the starting corridor; upon lifting of the guillotine door the animal chooses between going to the left or the right side of the arena and presses the corresponding lever. Lever pressing results in either the delivery of chocolate flavored sucrose pellets or no food delivery. Subsequent presses of the levers have no effect (retractable levers have also been used without any change in task performance). Each trial lasts $20 \mathrm{~s}$ after which the animal is hand-removed from the arena and placed back in the closed starting corridor. Then, a new trial will start after a variable inter-trial interval (ITI) of 5$10 \mathrm{~s}$ to prevent behavioral adjustment to the session limit. Trials in which the animal fails to press a lever within the 20 -s are counted as "incomplete."

Final $\mathrm{RGT}_{\text {reward probabilities }}$ testing consists of a single probe session of 90 trials. Reward contingencies associated with the levers are set so that one leads to frequent small rewards and the other to infrequent large rewards. Both levers have non-rewarded trials and both lead to similar long-term gains in a pseudo-random order, levers being counterbalanced between animals. Options are not "stacked" to favor reward delivery at the beginning of the session (see Fellows and Farah, 2005). During this test session, one lever remains at the reward settings of the training (one food pellet in 8 out of every 10 consecutive presses) while the other lever is set for rewarding three food pellets in 3 out of every 10 consecutive presses. The maximum gain of pellets per 10 trials is comparable 
for the low and high risk levers [ 8 vs. 9; but an equal maximum gain of nine pellets for both levers does not change task performance (Ji et al., 2010)]. As in the human IGT, control animals display a preference for the lever with infrequent large rewards in the beginning of the session, but shift their preference to the lever with frequent small rewards in the second half of the test.

\section{ONE SESSION CHOICE FOR HIGH REWARD/IMPROBABLE LONG PENALTIES VS. LOW REWARD/IMPROBABLE SHORT PENALTIES: THE FOUR-HOLE OPERANT CHAMBER MODEL \\ (RGT ONE SESSION REWARD AND TIME-OUT)}

Rivalan et al. (2009a) recently proposed an alternative automated rodent IGT in an operant chamber, with the goal to test complex decision-making processes within a single session, as in the original human IGT. This model offers the advantage to allow a rapid assessment of the decision-making process, measuring the timecourse of decisions, from random choice to a majority of choices for the preferred options, within $1 \mathrm{~h}$. Because decision-making can be measured in only one session, this task is particularly suitable for quickly identifying individual differences, or for the search of the neural bases of the time-course process of decision-making, using cellular brain imaging or PET scanning. Performances in this task are stable and reproducible (Rivalan et al., 2009a, 2011). This task can be solved by the majority of rats, whereas some poor decisionmakers that prefer larger immediate rewards despite suffering large losses can be identified, a result also observed in humans (Bechara et al., 1999, 2001; Bechara and Damasio, 2002; Davis et al., 2007; Glicksohn et al., 2007).

The test requires the rat to deduce, by trial and error, among four options, the two that are the more rewarding on the long-term and tracks the continuous and dynamic process of deduction and readjustment of choice. The principle of the task tightly mimics that of the human IGT: the contingencies are arranged so that the two options (holes chosen by nose-poking) that steadily offer bigger immediate food reward, are disadvantageous in the long run due to higher unpredictable penalties (frustrating time-outs during which no reward can be obtained). Inversely, the two advantageous options steadily offer smaller reward, but unpredictable penalties that can follow are shorter.

The testing apparatus (Figure 4) consists of an operant chamber lightly adapted from a standard five-hole operant chamber usually used for the five-choice serial reaction time task (Imetronic, Pessac, France). The adaptation consists of blocking the access to the central hole by a panel, and adding a transparent vertical partition containing a central opening that divides the chamber in half to allow an equal distance to each hole. The four holes, that can be dimly illuminated, are available on a curved wall, with a food dispenser on the opposite wall. The holes and food magazine are equipped with infrared sensors that detect nose-pokes. A program controls the chambers and collects the data.

Rewards are represented by the delivery of palatable food pellets (TestDiet, formula P), while punishments are associated with time-out periods, during which nose-pokes are inactive. As in the original IGT, each selection is rewarded, and some are also unpredictably punished. Similarly to $R G T_{\text {reward probabilities }}$, training for the acquisition of the basic operant responses is performed before testing. During these daily sessions (30 min each, repeated
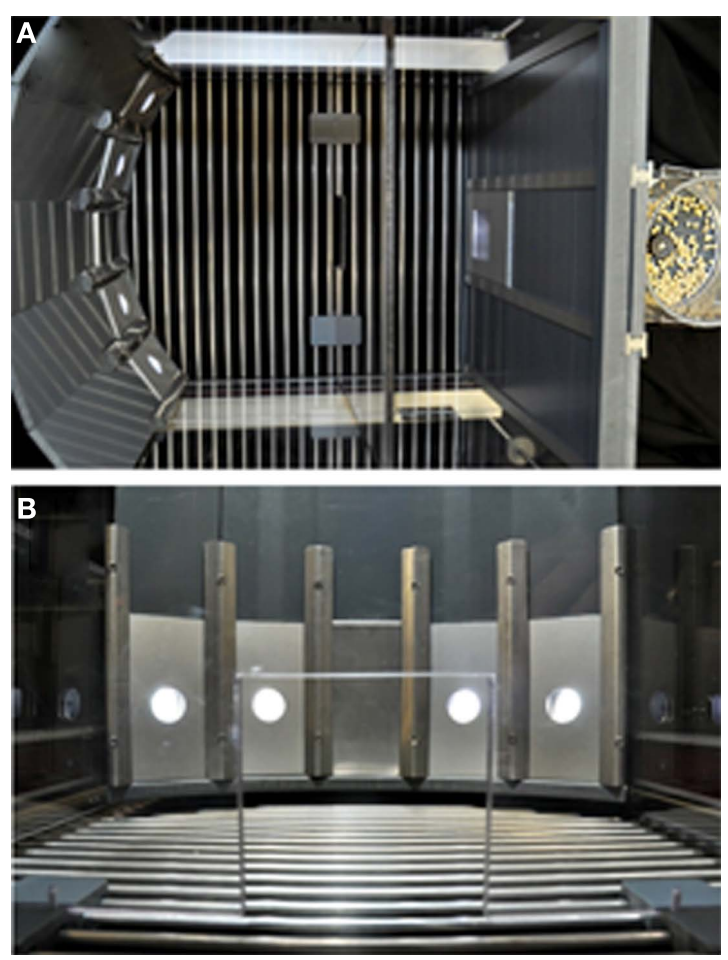

FIGURE 4 | The four-hole operant chamber model

(RGT one session reward and time-out). (A) Top view of the apparatus (Imetronic). These chambers are modular and can be configured for multiple behavioral paradigms (one or several nose-poke or levers, drug self-administration). A transparent vertical partition containing a central opening divides the chamber in half with four holes on a curved wall on a side, and a food dispenser on the opposite wall. (B) The four holes, that can be dimly illuminated, are equidistant from the central opening.

until a learning criterion is obtained within a session) animals are trained to associate two consecutive nose-pokes (ensuring voluntary choice performance) in any of the four illuminated holes with the delivery of one food pellet. Once the learning criterion is reached, animals are habituated to variable reward amounts (one/two pellets) per selection (two 15-min block per reward amount). Although a preference for a side could be observed individually, it has repeatedly been shown that this preference had no consequences on performances during test, nor differences in the level of exploration. Moreover, because palatable food pellets are used, food restriction facilitate training but is not necessary for testing (Rivalan et al., 2009a). During the subsequent test session ( $1 \mathrm{~h}$ of duration), animals are again requested to freely choose among the available options, but advantageous and disadvantageous selection schedules are now introduced. On one side of the curved wall, advantageous options are associated with the immediate delivery of only one pellet, that can eventually be followed by short time-outs ("deck C": 12 -s time-out $25 \%$ of the trials; "deck D": 6-s time-out $50 \%$ of the trials). These two choices result in the same theoretical maximum gain of about 300 pellets in $1 \mathrm{~h}$. On the other side of the curved wall, disadvantageous options correspond to two response holes that always provide two pellets as a reward upon selection, but that can eventually be followed by 
long time-outs ("deck A": 222 -s time-out $50 \%$ of the trials; "deck B": 444 -s time-out $25 \%$ of the trials). These two options have the same theoretical maximum gain of about 60 pellets in $1 \mathrm{~h}$. Punishments are assigned to each selection in a pseudo-random manner, so to maintain immediate outcome unpredictability, thus, options are not "stacked" to favor reward delivery at the beginning of the session (see Fellows and Farah, 2005). A choice also results in the deactivation of all stimulus-lights except for the chosen hole, until the reward is collected. This is particularly important during the time-outs to facilitate the association between hole response and its consequences. Based on the reinforcement schedule employed during testing, choosing either advantageous or disadvantageous options during this session would result in a theoretical overall payoff ratio of 5.00 (300 or 60 pellets per response hole, considering a standard trial duration of $9 \mathrm{~s}$ ). The task difficulty can be easily modified, i.e., decreasing the ratio to 3 by increasing time-out duration associated with favorable options, that lead to a slower decision-making process (see Rivalan et al., 2009a).

\section{MULTIPLE SESSION CHOICE FOR CONFLICT BETWEEN OPTIONS VARYING IN REWARD AND TIME-OUT FREOUENCY AND DURATION: THE FIVE-HOLE OPERANT CHAMBER MODEL (RGT REWARD OR TIME-OUT)}

This rodent gambling task also signals loss on non-rewarded trials through the presentation of frustrating time-out periods, and uses sucrose pellets as a reward. This model presents the animals with a choice between four distinct options on each trial which are loosely analogous to the four deck of cards in the IGT, i.e., the options differ in terms of the probability and magnitude of expected gains and losses, such that the two options which deliver the smaller units of reward are ultimately advantageous. However, this model differs both in the duration of training, the reinforcement contingencies associated with the different options and the way in which the task is learned. Although both the $\mathrm{RGT}_{\text {one session reward and time-out }}$ and $\mathrm{RGT}_{\text {reward or time-out }}$ are complementary, they also have different strengths and can be best used to answer different questions. Notably, the RGT reward or time-out model was designed in a manner that could be optimized for behavioral pharmacology experiments and other manipulations, which benefit from repeated daily testing.

Testing takes place in standard five-hole operant chambers available from a number of vendors (e.g., Med Associates, Coulbourn; the same chambers used for the five-choice serial reaction time task; Figure 5). The defining feature of such boxes is that an array of five stimulus-response holes is located on one wall of the chamber, although only four holes are used during the task. Each response hole can be illuminated by a stimulus light located therein, and nose-poke responses into a hole are detected by an infrared sensor. A food tray, also equipped with an infrared sensor and a tray light, is located in the middle of the opposite wall, into which sucrose pellets can be delivered via an external pellet dispenser. The entire chamber can also illuminated using a house-light.

As is often standard for operant-based tasks, animals are first trained to make the basic operant response, in this case to make a nose-poke response into a single illuminated response hole within $10 \mathrm{~s}$. Animals are then trained on a forced-choice version of the task for five to seven sessions, during which only one of the four possible options is presented on each trial (Zeeb et al., 2009; Zeeb

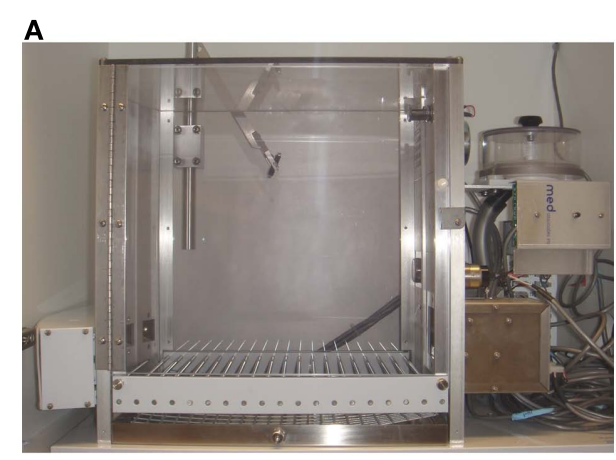

B

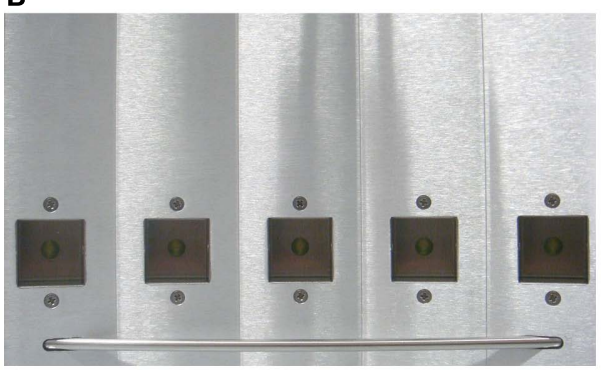

FIGURE 5 | The standard five-hole operant chamber, as used for the $\mathbf{R G T}_{\text {reward or time-out }}$ model. (A) Side view of a Med Associates five-hole box. These chambers are modular and can be configured for multiple behavioral paradigms and manipulations, hence the arm assembly for drug self-administration/microdialysis and additional levers visible. However, these components are not necessary for the RGT. (B) A close-up of the standard five-hole array showing stimulus light location and infrared beam.

and Winstanley, 2011). This training stage ensures that all animals equally experience each of the four reinforcement contingencies, in order to prevent simple biases toward a particular hole from developing. Although this forced-choice contingency does not occur in the IGT, subjects are verbally instructed that there are decks which result in greater losses than others and that winning may be accomplished if the worst decks are avoided (Bechara et al., 1999).

Following forced-choice training, all animals are then tested on the free-choice task, where all four options are presented (i.e., all four response holes are illuminated). Training occurs once daily, and each session lasts for $30 \mathrm{~min}$. Animals initiate each trial by making a nose-poke response into the illuminated food tray. This response initiates a 5-s ITI, where all lights are off and the chamber is in darkness. A nose-poke response in any hole of the array during this time is termed a premature response - a measure of motor impulsivity - and is signaled by illumination of the house-light for $5 \mathrm{~s}$. The animal must then re-start another trial (by making a nosepoke response in the illuminated food tray). This measurement is analogous to that of the premature responses measured in the five-choice serial reaction time task (Robbins, 2002). Therefore, for the first time, both motor impulsivity and decision-making can be concurrently assessed - and dissociated - within the same task (Zeeb et al., 2009).

At the end of the ITI, four holes are concurrently illuminated (left to right: holes 1, 2, 4, and 5) for a maximum of $10 \mathrm{~s}$. The animal signals its preference by nose-poking in one of the illuminated holes, at which point all the stimulus-lights are then extinguished. 
If the trial is rewarded, the tray light illuminates and the corresponding number of sucrose pellets are delivered immediately. As in the five-choice serial reaction time task, responding at the food tray to collect reward also initiates the next trial. However, if the trial is a loss, no reward is delivered and a time-out period begins during which the light in the hole chosen flashes at a frequency of $0.5 \mathrm{~Hz}$. The animal is unable to initiate any more trials or earn reward until the time-out is over, at which the animal can initiate the next trial by responding in the now-illuminated food tray. The reinforcement contingency linked to each option (response hole) varies in terms of both the number of sugar pellets available, and the duration and probability of a punishing time-out period. The probability of receiving reward or punishment remains constant throughout each session, i.e., the options are not "stacked" to favor reward delivery at the beginning of the session (see Fellows and Farah, 2005). The spatial location of these options are balanced, such that one advantageous and one disadvantageous option is located on each side of the chamber, therefore the correct strategy cannot be reduced to a side bias. The optimal strategy is to select the two-pellet option ( $\mathrm{P} 2)$, associated with a 10 -s time-out period that occurs $20 \%$ of the time ( $80 \%$ chance of winning). The next best option is P1 ( $5 \mathrm{~s}$ time-out, $90 \%$ chance of winning). The two highly disadvantageous options are both associated with larger immediate gain - three or four sucrose pellets - but also longer time-out periods (P3: 30 s time-out, 50\% chance of winning; P4: 40 s time-out; $40 \%$ chance of winning). Occurrence of gains and losses on each trial is determined pseudo-randomly to ensure a constant distribution of gains and losses throughout each session.

It is possible to calculate the hypothetical amount of reward that could be obtained if an option is chosen exclusively in a 30min training session, and if each trial is initiated and performed as quickly as possible (i.e., within $5 \mathrm{~s}$; Zeeb et al., 2009). Based on these calculations, persistent selection of the optimal choice (P2) yields a hypothetical maximum of 411 sugar pellets, whereas P1 yields 295 pellets. The two disadvantageous options are associated with significantly less possible reward (P3: 135 pellets; P4: 99 pellets). Therefore, the optimal strategy is to prefer the advantageous options - P2 and P1 - which are associated with smaller, immediate gain, but also less punishment resulting in more reward in the long-term, while avoiding the tempting, yet disadvantageous, large reward options associated with greater loss $-\mathrm{P} 3$ and P4.

\section{RGT VALIDITY}

\section{CRITERIA FOR THE VALIDITY OF AN ANIMAL MODEL}

The goal of an animal model of human decision-making is to develop, in laboratory animals, behavior that closely resembles that observed in human subjects, thereby allowing researchers to translate findings across species. The validity of animal models depends on the strict definition of its potential applications, taking into account the models' biases and limits. This validity is commonly assessed using the concept of face, construct and predictive validities (McKinney and Bunney, 1969; Willner, 1995). Face validity refers to similarities between animals and humans in symptomatology, construct validity concerns similarities in underlying psychobiological and physiological processes, and predictive validity concerns the model's potential to predict these processes in human, most often with regards to identifying efficient pharmacological compounds in humans. With respect to face validity, numerous studies using the IGT in both healthy and patient populations provide knowledge regarding task performance and distinct behavioral patterns of impairment that allows direct comparison to response patterns in the rodent tasks. However, when it comes to construct and predictive validities, current knowledge from pharmacological or imaging human studies is incomplete, making these attributes more difficult to assess. The gap in our current understanding of the neurobiological underpinnings of decision-making in fact underlines the need for animal models that allow more thorough and controlled investigation of these mechanisms.

\section{FACE VALIDITY OF THE RGTS Response patterns in RGTs}

In all four RGTs, despite the considerable differences in task characteristics, animals were able to evaluate which options are advantageous in the long-term, and to adapt their choice behavior accordingly. Although the end point of behavioral testing differed across tasks, from decision-making measure during a single session to a multiple session learning process, most rats finally developed a significant preference for the more advantageous options (van den Bos et al., 2006; Pais-Vieira et al., 2007, 2009; Homberg et al., 2008; Zeeb et al., 2009; de Visser et al., 2011b; Zeeb and Winstanley, 2011), as also observed in C57BL/6 mice employing the eight-arm radial maze model (van den Bos et al., 2006) and mice performing a version very similar to RGT reward or time-out (Young et al., 2011).

In $\mathrm{RGT}_{\text {reward or quinine }}$ rats start off with an explorative search profile, displaying equal preference for either the advantageous or disadvantageous arm. After 60-80 trials, a stable preference for the advantageous arm emerges. Rats' performance of

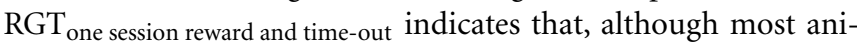
mals learn the contingencies and gradually develop a preference for the advantageous options (Rivalan et al., 2009a), about $40 \%$ of the animals failed to solve the task, either because they did not develop any option preference, or because they developed a significant preference for disadvantageous options. These interindividual differences are stable across time, and reproducible across groups. Interestingly, failure to solve the IGT by a portion $(20-30 \%)$ of healthy humans has also been observed (Bechara et al., 1998, 2001, 2002; Crone and van der Molen, 2004; Dunn et al., 2006). These individuals have been characterized as impulsive and sensation-seekers (Davis et al., 2007; Franken et al., 2008), some behavioral traits that are related to those of poor decisionmakers in rats, i.e., risk-taking and sensitivity to reward (Dellu et al., 1993, 1996; Rivalan et al., 2009a).

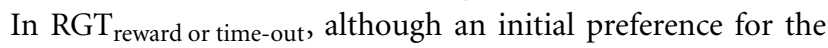
advantageous options is already established in the initial training sessions, this preference continues to develop as testing proceeds. In this experimental design, learning of options' contingencies is made prior the decision-making test, by systematically exposing animals to the task contingencies during forcedchoice training sessions (Zeeb et al., 2009). This ensures that all animals have equal exposure to the different reinforcement contingencies associated with all the options, and theoretically prevents the development of any biases due to inadequate sampling. As a result, it can be argued that performance in this task predominantly captures the second phase of the IGT when contingencies are known (exploitation), particularly later in training 
when performance has stabilized. However, the fact that choice between the options still varies between sessions earlier in training implies that learning (exploration) still occurs. Furthermore, recent evidence suggests that acquisition and performance of this task is controlled by somewhat dissociable neural circuitry (Zeeb and Winstanley, 2011) which supports the distinction between brain areas involved in exploration vs. exploitation outlined in Section "Neural Substrates."

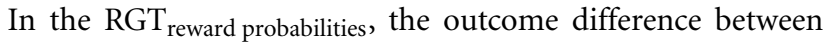
advantageous and disadvantageous options is minimal (8 vs. 9 pellets), an inconsistency with respect to the human IGT where choice options have marked long-term outcome differences. As such, this task may be more similar to models of probability discounting (e.g., St Onge and Floresco, 2009b) and other aspects of decision-making under uncertainty, rather than the IGT. Nevertheless, control rats preferentially choose smaller but more reliable rewards over larger unreliable rewards, similar to the choice pattern observed in humans. In summary, in all four RGTs animals are able to learn which options are advantageous in the longterm, but the nature of the learning patterns differs between the tasks. This source of variation could be used to address more specifically one aspect of a deficit in animal models of psychiatric conditions, as observed in mental disorders. For example, preference for disadvantageous options, as observed in schizophrenia, OCD, pathological gambling, substance abusing individuals, or $\mathrm{ADHD}$, can be tested in RGTs with a high ratio between advantageous vs. disadvantageous options; slower IGT decision-making in maniac or substance-dependent individuals could be addressed

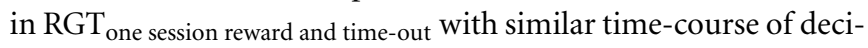
sion process; sensitivity to the frequency of the punishment as observed in ADHD or schizophrenic patients (Shurman et al., 2005; Toplak et al., 2005) could be assessed in RGT reward probabilities.

\section{Influence of sex and inter-individual differences on RGT performance}

The only task which has been used to study sex differences to date is

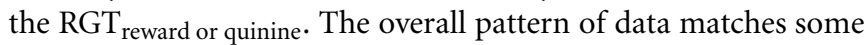
findings in humans in that females display poorer performance as compared to males (Reavis and Overman, 2001; Bolla et al., 2004; van den Bos et al., 2007; de Visser et al., 2010). Both in rats and humans, sex differences emerge in the second part of the task and have therefore been related to diminished cognitive control in females vs. males (van den Bos et al., 2007; de Visser et al., 2010).

Based on findings from human IGT studies, it is well established that inter-individual differences in personality traits, such as trait anxiety, risk-taking, and impulsivity affect performance. The relationship between certain individual trait differences and decision-making performance has been investigated in both

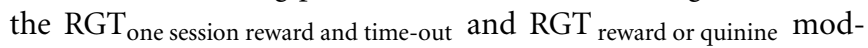
els. Associations between risk-taking, reward sensitivity, and IGT performance were demonstrated in male Wistar rats in the $\mathrm{RGT}_{\text {one session reward and time-out }}$ (Rivalan et al., 2009a). When compared to good decision-makers, animals performing poorly in this task were also more sensitive to rewards, as they ran faster to obtain a food reward in a runway paradigm and sustained higher amounts of effort to earn food in the context of a progressive ratio schedule of food reinforcement. Moreover, these individuals were more risk-prone, exposing themselves more frequently to potentially dangerous environments in the light/dark emergence test (highly illuminated compartment; Dellu et al., 1993) and in the elevated plus-maze test (external third of the open arms; Rivalan et al., 2009a). These data are consistent with findings from healthy human studies, showing that poor IGT performers also exhibit riskier choice patterns in two tasks assessing decision-making under risk, the Game of Dice Task (Brand et al., 2007b) and the Cups task (Weller et al., 2010), and the observation that in both healthy and clinical populations exhibiting poor decision-making, reward hypersensitivity appears to underlie deficits in IGT performance (Must et al., 2006; Davis et al., 2007; Suhr and Tsanadis, 2007; Kobayakawa et al., 2010). Furthermore, abnormal levels of risk-taking and hypersensitivity to reward are found in psychiatric disorders associated with poor decision-making and impulsivity, such as ADHD, substance abuse, pathological gambling, or mania (Mazas et al., 2000; Bechara et al., 2001; Drechsler et al., 2008; Kathleen Holmes et al., 2009). Hence, it could be argued that poor decision-making in both humans and rats may stem from common risk factors to develop these disorders.

In a recent study, high levels of anxiety as measured with standard parameters in the elevated plus-maze (\% time and visits in open arms) has been associated with poor decision-making using the $\mathrm{RGT}_{\text {reward or quinine }}$ model (de Visser et al., 2011b). Based on a detailed analysis of rat choice strategies, it was suggested that highly anxious subjects may have a shifted bias toward responding to the negatively valued stimuli, i.e., the quinine pellets, and under-appraised the positively valued stimuli, i.e., the sucrose rewards, leading to suboptimal decision-making. These findings are in line with human data, in that highly anxious healthy subjects performed worse on the IGT compared to their less anxious counterparts (de Visser et al., 2010). These reports also highlight the potential confound in the human data, in that both high anxiety (preferentially measured in the experimental paradigm of de Visser et al., 2011b), and high risk seeking (preferentially measured by Rivalan et al., 2009a) are associated with poor IGT performance, an issue that animal models may be able to resolve, and future work will no doubt address the biological basis of these findings.

Taken together, RGT performance, similar to the IGT, is associated with inter-individual differences related to sex differences and behavioral traits. The study of these inter-individual differences provide a reliable and valuable tool to investigate, for instance, the neurobiological features of subjects at risk to develop mental disorders related to poor decision-making.

\section{CONSTRUCT VALIDITY OF THE RGTs}

Construct validity of the RGTs can be evaluated based on the partial knowledge of the neurobiological mechanisms underlying IGT performance in humans. Key brain areas have been identified from lesion and imaging studies that include parts of the prefrontal cortex, the ventral striatum, and limbic structures such as the amygdala (see Neural Substrates). Furthermore, gene polymorphisms related to serotonergic and dopaminergic systems have been identified that modulate IGT performance and affect the function of corticolimbic neural circuits. Thus, construct validity of the RGTs will be discussed based on these findings (see Table 2 for overview). 
Table 2 | Effect of manipulations on rodent IGT performance.

\begin{tabular}{|c|c|c|c|c|}
\hline Manipulation & $\mathbf{R G T}_{\text {reward or quinine }}$ & $\mathbf{R G T}_{\text {reward probabilities }}$ & $\mathbf{R G T}_{\text {one session reward and time-out }}$ & $\mathbf{R G T}_{\text {reward or time-out }}$ \\
\hline \multicolumn{5}{|l|}{ C-FOS } \\
\hline Orbitofrontal cortex & $\begin{array}{l}\text { No dissociation between } \\
\text { good and bad performers } \\
\text { (de Visser et al., 2011 b) }\end{array}$ & & $\begin{array}{l}\text { Dissociation good and bad } \\
\text { performers Fitoussi et al. (in } \\
\text { preparation) }\end{array}$ & \\
\hline $\begin{array}{l}\text { Medial prefrontal } \\
\text { cortex }\end{array}$ & $\begin{array}{l}\text { Dissociation good and bad } \\
\text { performers (de Visser } \\
\text { et al., 2011b) }\end{array}$ & & $\begin{array}{l}\text { Dissociation good and bad } \\
\text { performers Fitoussi et al. (in } \\
\text { preparation) }\end{array}$ & \\
\hline Ventral striatum & $\begin{array}{l}\text { Dissociation good and bad } \\
\text { performers (de Visser } \\
\text { et al., 2011 b) }\end{array}$ & & $\begin{array}{l}\text { Dissociation good and bad } \\
\text { performers Fitoussi et al. (in } \\
\text { preparation) }\end{array}$ & \\
\hline \multicolumn{5}{|c|}{ LESIONS/INACTIVATIONS } \\
\hline Orbitofrontal cortex & & $\begin{array}{l}\text { Increased choice of higher } \\
\text { risk option during } \\
\text { exploitation phase } \\
\text { (Pais-Vieira et al., 2007) }\end{array}$ & $\begin{array}{l}\text { Perseverative responding } \\
\text { (Rivalan et al., 2011) }\end{array}$ & $\begin{array}{l}\text { Lesion before acquisition: } \\
\text { delayed development of pref- } \\
\text { erence for the correct option. } \\
\text { Lesion afer acquisition: no effect } \\
\text { (Zeeb and Winstanley, 2011) }\end{array}$ \\
\hline Prelimbic cortex & & & $\begin{array}{l}\text { Inability to chose between good } \\
\text { and bad options, or inflexibility } \\
\text { (Rivalan et al., 2011) }\end{array}$ & \\
\hline $\begin{array}{l}\text { Anterior cingulate } \\
\text { cortex }\end{array}$ & & & $\begin{array}{l}\text { Delayed good decision-making } \\
\text { (Rivalan et al., 2011) }\end{array}$ & \\
\hline $\begin{array}{l}\text { Medial prefrontal } \\
\text { cortex }\end{array}$ & $\begin{array}{l}\text { Impaired task-progression } \\
\text { during exploitation phase } \\
\text { (de Visser et al., 2011b) }\end{array}$ & & & \\
\hline Amygdala & & & & $\begin{array}{l}\text { Lesion before acquisition: } \\
\text { delayed development of pref- } \\
\text { erence for the correct option. } \\
\text { Lesion after acquisition: Increase } \\
\text { in preference for the disad- } \\
\text { vantageous options (Zeeb and } \\
\text { Winstanley, 2011) }\end{array}$ \\
\hline
\end{tabular}

\section{GENETIC ALTERATIONS}

SERT knockout rat

Increased choice of

advantageous option

during exploitation phase

(Homberg et al., 2008)

DAT knockout

Increased choice of the disadvan-

mouse tageous/risky options

\section{PHARMACOLOGY}

8-OH-DPAT (5-HT 1 A

agonist)

SKF 81297 and

Less advantageous choices (Zeeb et al., 2009)

quinpirole or

bromocriptine $\left(D_{1}\right.$,

$D_{2 / 3}$ agonists)

Eticlopride $\left(D_{2}\right.$

antagonist)

Amphetamine

No effect (Zeeb et al., 2009)

NBI27914 (CRF1

antagonist)
Intra amygdala

administration (BLA)

reversed poor performance

(Ji et al., 2010)
Improved choice advantageous option (Zeeb et al., 2009)

Increased choice of less advantageous options (Zeeb et al., 2009) 


\section{Serotonergic system and RGT}

It is possible to draw a parallel between performances of rats lacking the SERT in the $\mathrm{RGT}_{\text {reward or quinine (Homberg et al., 2008) }}$ and the 5-HTTLPR (serotonin-transporter-linked polymorphic region) IGT studies in humans. Homozygous $\left(\mathrm{SERT}^{-1-}\right.$ ) and heterozygous $\left(\mathrm{SERT}^{+-}{ }^{-}\right.$) knockout rats are suggested to model stressed and unstressed 5-HTTLPR s-allele carriers, while wildtype control rats may correspond to 5-HTTLPR l-allele carriers (Kalueff et al., 2009; Homberg and Lesch, 2010). SERT ${ }^{-I-}$ and SERT ${ }^{+-}$rodents show gene-dose-dependent increases in extracellular serotonin levels due to reduced serotonin reuptake (Homberg et al., 2007). It was found that SERT ${ }^{+/-}$and SERT ${ }^{-/-}$ rats demonstrated better decision-making compared to SERT ${ }^{+/+}$ animals, particularly in the second half of the trials. This seemingly contrasts findings that human 5-HTTLPR s-allele carriers performed worse during the task compared to $1 / 1$ subjects (Must et al., 2007; da Rocha et al., 2008; Homberg et al., 2008; van den Bos et al., 2009b; He et al., 2010). If serotonin modulates vigilance and is responsible for the integration of relevant environmental stimuli (Branchi, 2010; Homberg and Lesch, 2010), this discrepancy may be reconciled by the fact that $\mathrm{RGT}_{\text {reward or quinine }}$ employs two baited choice options, as opposed to four in the human IGT.

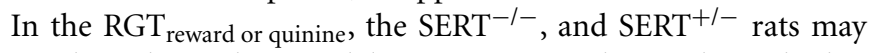
not have been distracted by environmental stimuli, such that they could focus on their long-term goal: obtaining maximum gain. It would be interesting to test this hypothesis in one of the RGT models which require animals to discriminate between four options concurrently, such as the RGT one session reward and time-out or $\mathrm{RGT}_{\text {reward or time-out }}$.

\section{Dopaminergic system and RGT}

As discussed earlier, increased choice of the disadvantageous options on the IGT has been reported in bipolar patients. Reduced dopamine transporter (DAT) function has been hypothesized as a contributing factor to bipolar disorder on the basis of both genetic linkage studies (Kelsoe et al., 1996; Greenwood et al., 2001, 2006) and analysis of DAT expression in patients (Horschitz et al., 2005). Using a mouse version of the $\mathrm{RGT}_{\text {reward or time-out }}$, increased choice of the disadvantageous, or risky, options has been observed in mice lacking the DAT (Young et al., 2011). Furthermore, this risky decision-making correlated with specific exploratory activity in a mouse behavioral pattern monitor (BPM), a pattern of motor behavior that is also observed in acutely manic patients (Perry et al., 2009). Hence, this RGT model has proven useful in demonstrating similar behavioral phenotypes in a putative mouse model of bipolar disorder as compared to the clinical condition.

\section{Prefrontal cortex and RGT}

Evidence of involvement of the prefrontal cortex in rodent IGTlike decision-making was reported in three RGT studies. OFC lesioned animals preferred the higher risk lever during the second

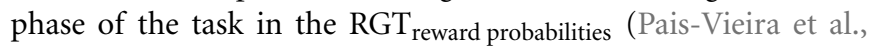
2007). This is in accordance with impaired decision-making and high risk-taking observed in human patients with damage to the vmPFC (Bechara et al., 2000; Clark et al., 2008), and the relationships between OFC activity and IGT performance in healthy subjects in fMRI studies (Bolla et al., 2004; Lawrence et al., 2009).
Theoretically, OFC lesion effect on risk-taking could be expressed in the $\mathrm{RGT}_{\text {reward probabilities, }}$, since this task is based on a two-option simple choice as opposed to the $\mathrm{RGT}_{\text {one session reward and time-out }}$ (Rivalan et al., 2011). In this latter task, measure of risk-taking is combined with the capacity to perceive the changes in contingencies between training (all options have the same consequences) and test (four different consequences), a function also associated with OFC (see below). Consequently, OFC lesioned rats exhibited perseverative responding, as if they failed to encode the change in contingency. This was demonstrated by an absence of sampling of the four options at the beginning of the test, and a marked preference for the holes on the side that they preferred during training. Such inflexible responding following OFC lesions has been reported multiple times, particularly in the context of impaired reversal learning (Dias et al., 1996; Schoenbaum et al., 2002; McAlonan and Brown, 2003; Ragozzino, 2007; Rudebeck and Murray, 2008; Kazama and Bachevalier, 2009; Robbins and Arnsten, 2009). Indeed, the original demonstration that vmPFC-damaged patients were impaired on the IGT used stacked decks, such that no losses were experienced in the first block of trials, and all subjects initially preferred the large reward decks (Bechara et al., 1999). Patients with comparable vmPFC damage were not impaired on a "shuffled" version of the IGT, in which gains and losses were distributed randomly through the decks, suggesting that the original impairment arose from patient's inability to switch preferences away from the disadvantageous decks once punishments were introduced (Fellows and Farah, 2005). Considerable evidence suggests that this region is critical in generating outcome expectancies, and updating them as the reward value of available options changes (for review see Schoenbaum et al., 2009). Notably, the degree of OFC involvement may depend on the level of ambiguity experienced by the subject, i.e., the OFC may be important when individuals are learning the reinforcement contingencies and ambiguity is high. Once uncertainty becomes expected, such that the individual figures out the odds of risk and reward associated with each option, the OFC may play less of a role in maintaining the optimal choice strategy. This hypothesis is supported by recent findings using $\mathrm{RGT}_{\text {reward or time-out }}$ in which OFC lesions performed prior to acquisition of the task slowed learning such that rats took longer to develop a strong preference for the correct option (Zeeb and Winstanley, 2011). However, if lesions were performed once the task had already been learned, then no choice impairment was

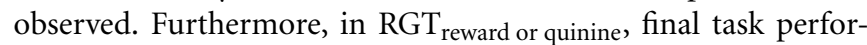
mance was not related to OFC activation, as measured by the levels of expression of the immediate early gene c-fos (de Visser et al., 2011b), again indicating that activity within the OFC is not a critical determinant of decision-making under risk. Conversely, under

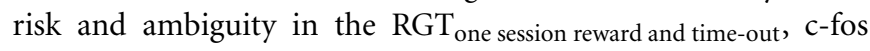
expression differentiated between good and poor decision-makers (Fitoussi et al., in preparation).

In addition to the OFC, damage to two areas of the medial PFC (mPFC) were found to affect performance of the

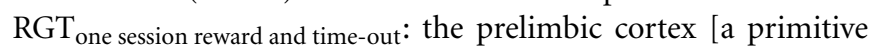
version of the dlPFC of the primate (Vertes, 2006)] and the ACC (Rivalan et al., 2011). Lesions of the ACC mainly delayed good decision-making in this task whereas lesions of the prelimbic cortex either led to an inability to chose between good and bad 
options (undecided behavior) or induced inflexibility in behavior, similarly to OFC lesions. Moreover, c-fos activity in the mPFC was found to differentiate between good and poor performers in the $\mathrm{RGT}_{\text {reward or quinine }}$ and $\mathrm{RGT}_{\text {one session reward and time-out (de Visser }}$ et al., 2011b; Fitoussi et al., in preparation). Interestingly, the rat mPFC shares anatomical and functional homology with the ACC and dlPFC in humans (Uylings and van Eden, 1990; Brown and Bowman, 2002; Uylings et al., 2003). These areas are involved in IGT performance in humans (Ernst et al., 2002; Bolla et al., 2004; Fukui et al., 2005; Lin et al., 2008; Lawrence et al., 2009). The ACC and dlPFC are specifically involved in a negative feedback circuit of cortical control over limbic areas (Ridderinkhof et al., 2004; Bechara et al., 2005). This top-down cognitive control circuit controls decision-making on the basis of reward and punishment (Quirk et al., 2000; Miller and Cohen, 2001; Rogers et al., 2004; St Onge and Floresco, 2009a; Davis et al., 2010) and is suggested to mediate predominantly the second part of the IGT, when a preference for the advantageous decks has developed and performance is mainly characterized by maintenance and exploitation of the advantageous choice strategy (van den Bos et al., 2007). Thus, activation differences in the mPFC in rats in the RGT may be related to a weaker cognitive control system in poor vs. good performers. In line with the aforegoing, inactivation of the mPFC using a mixture of GABA-agonists muscimol and baclofen, hampered task-progression in those animals which already showed task-learning but not in those animals which were still in the exploratory phase of the task (de Visser et al., 2011a). Further experiments are needed to substantiate the role of the MPFC in decision-making using the different RGT models.

\section{Sub-cortical areas and RGT}

Apart from cortical areas, the ventral striatum was found to be differentially recruited in good vs. poor performers in

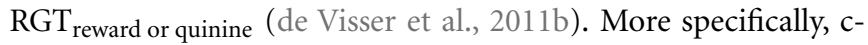
fos induced activation was higher in the nucleus accumbens core $(\mathrm{NaC})$ but lower in the nucleus accumbens shell $(\mathrm{NaS})$ in good performers compared to poor performers, suggesting distinct roles for the nucleus accumbens subareas in rat decision-making. As Yin et al. (2008) argued, the $\mathrm{NaC}$ may be involved in more advanced decision-making processes than the shell, thus reflecting the more advanced performance of the good decision-makers. Moreover, the $\mathrm{NaC}$ has been implicated in impulse control and behavioral flexibility (Cardinal et al., 2001; Christakou et al., 2004; Pothuizen et al., 2005; Floresco et al., 2006), but see (Murphy et al., 2008), which may suggest that good decision-makers are better at developing a behavioral strategy that is directed to the long-term gain of the advantageous option as opposed to the immediate gain of the disadvantageous option.

The amygdala has also been associated with IGT performance, in that patients with bilateral lesions to this brain region showed a very similar pattern of choice on the IGT as vmPFC patients, choosing more often from the disadvantageous decks (Bechara et al., 1999). A similar pattern of choice has recently been observed

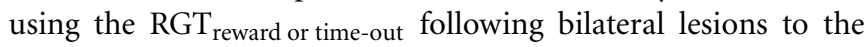
BLA, in that lesions made after animals had acquired the task lead to an increase in preference for the disadvantageous options. Interestingly, lesions made prior to acquisition of the task strongly resembled the effects of OFC lesions made at the same time point, in that both groups of lesioned animals were slower to adopt the correct strategy as compared to sham controls (Zeeb and Winstanley, 2011). Such data suggest that the OFC and BLA may be working together to optimize choice behavior when the odds of reinforcement are still unclear. These results are in accordance with the finding that the level of ambiguity in choices was positively correlated with the level of activity in the OFC and amygdala (Hsu et al., 2005; Lawrence et al., 2009). The fact that BLA lesions still affected decision-making once the task had been learned suggests that decreased activity in this region may precipitate an increase in risky choice, and that this area is involved in maintaining an optimal decision-making strategy under risk even after the cost-benefit contingencies have been acquired.

In conclusion, neural circuitry comprising the PFC, striatum, and amygdala appears to modulate decision-making in RGT models, and the effects observed are largely consistent with findings in humans. Altered connectivity between cortico-striatal-limbic circuitry has been implicated in various disorders, such as schizophrenia, drug addiction, OCD, and anxiety disorders. The RGTs may therefore contribute to an increased understanding of the pathophysiology of these disorders. Comparing the findings of lesion and c-fos activation studies across the RGT models will help to further validate their use, and may provide new insight into the neural circuitry involved in this form of decision-making. Moreover, the somatic marker hypothesis could be addressed in all the RGTs during the exploration phase of the tasks, i.e., when choices evolve with time before reaching a stable level (exploitation phase). Measures of blood pressure, heart rate, associated with behavioral activity could serve as somatic markers in freely moving rats, by radiotelemetry.

\section{PREDICTIVE VALIDITY OF THE RGTS}

Given that low serotonin (5-HT) function has been observed in problem gamblers, and that selective 5-HT reuptake inhibitors are currently used as a treatment for this disorder, Zeeb et al. (2009) investigated the effects of acutely decreasing 5 -HT release using the $5-\mathrm{HT}_{1 \mathrm{~A}}$ receptor agonist $8-\mathrm{OH}$-DPAT on performance of the

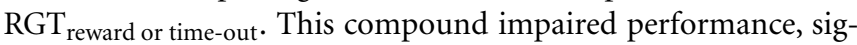
nificantly increasing choice of less advantageous options (P1, P3) and decreasing choice of the best option (P2). These effects were effectively blocked by co-treatment with the highly selective 5$\mathrm{HT}_{1 \mathrm{~A}}$ receptor antagonist WAY100635. However, it remains to be established whether these effects are due to activation of inhibitory $5-\mathrm{HT}_{1 \mathrm{~A}}$ receptors located pre-synaptically in the raphe nuclei, or post-synaptically in limbic and cortical brain regions.

In addition to the effects of acute 5-HT manipulations, the effects of receptor-specific dopamine agonists and antagonists have also been explored using $\mathrm{RGT}_{\text {reward or time-out }}$ (Zeeb et al., 2009). Interestingly, $D_{1}$ and $D_{2} / D_{3}$ receptor agonists (SKF 81297 and quinpirole or bromocriptine) did not affect animals' choice preferences on the task. However, acute administration of the $\mathrm{D}_{2}$ receptor antagonist, eticlopride, significantly improved task performance by increasing the animals preference for the optimal option (P2) while decreasing choice of both high reward-high punishment options (P3, P4). This effect appears to be selective to the blockade of $D_{2}$ receptors, as administration of a $D_{1}$ receptor 
antagonist, SCH 23390, did not alter decision-making (Zeeb et al., 2009).

The psychostimulant amphetamine has been shown to prime the motivation to play slot machines in pathological gamblers (Zack and Poulos, 2009). Amphetamine treatment significantly impaired the animals' ability to perform the $\mathrm{RGT}_{\text {reward or time-out }}$ optimally. However, in contrast to the effects of the $5-\mathrm{HT}_{1 \mathrm{~A}}$ receptor agonist 8-OH-DPAT, amphetamine caused animals to become more punishment/loss-sensitive, illustrated by an increased preference for P1, the option with the smallest amount of immediate reward, but also the least amount (frequency and duration) of punishment. Therefore, amphetamine may amplify animals' sensitivity to punishment (Zeeb et al., 2009). Although this behavior cannot necessarily be classified as "risky," placing too much emphasis on a potential loss may be unfavorable in the longterm (Kuhnen and Knutson, 2005) and can contribute to losschasing behavior in real-life gambling situations (see discussion in Campbell-Meiklejohn et al., 2008).

Overall, there are both similarities and discrepancies when comparing these results to human findings. As previously discussed, high levels of prefrontal dopamine and corticolimbic 5-HT levels may correlate with worse IGT performance. Therefore, the fact that amphetamine impaired decision-making on $\mathrm{RGT}_{\text {reward or time-out }}$ supports the hypothesis that increased levels of dopamine or 5-HT impairs decision-making. However, acutely decreasing dopamine levels in healthy volunteers by BCAA administration causes subjects to choose the disadvantageous options on the IGT, especially during the exploitation phase of testing (Sevy et al., 2006). One explanation provided by Zeeb et al. (2009), is that the effects of various drug manipulations may rely on both the basal levels of dopamine as well as task-related changes in dopamine release. Therefore, the effects of dopamine, and perhaps 5-HT, may follow an inverted U-shaped curve (see Neuromodulators). Interestingly, it is unclear whether an acute dose of eticlopride is modulating activity of inhibitory $\mathrm{D}_{2}$ autoreceptors and/or post-synaptic receptors. A blockade of $\mathrm{D}_{2}$ autoreceptors may stimulate the firing of dopaminergic neurons, while suppressing dopamine transmission post-synaptically (Seamans and Yang, 2004). The net effect may be an enhancement of prediction error signals, which would thus improve decision-making. It should be noted that high PFC dopamine levels are proposed to enhance exploration in the direction of alternative options that might yield higher gains (Frank et al., 2009); however pharmacological manipulations were performed once animals had been

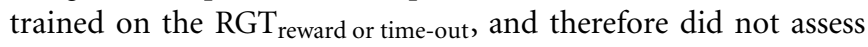
the ability of these drugs to alter task acquisition.

As amphetamine increased the saliency of the punishment signals in $\mathrm{RGT}_{\text {reward or time-out, }}$ it may be suggested that this effect was caused by an abnormal increase in dopamine. However, this explanation contrasts with the finding that COMT Met/Met individuals have an attentional imbalance in favor of rewards (van den Bos et al., 2009b). One possible explanation is that amphetamine may be causing rats to become more risk-averse through increases in other neurotransmitters (such as 5-HT). Another possibility is that animals received an acute treatment in the study by Zeeb et al. (2009), whereas the human subjects tested in the study by van den Bos et al. (2009a) was observing the effects of long-term genetic abnormalities. Furthermore, the COMT polymorphism is known to target the prefrontal cortex, whereas an acute dose of amphetamine would have more widespread effects.

5-HT mediates a variety of central processes, such as emotionregulation, learning and memory, motivation, and behavioral inhibition; these traits may be unified by sensitivity to external and internal environmental stimuli, and integrated in order to facilitate associative learning processes (Branchi, 2010; Homberg and Lesch, 2010). While serotonin may modulate behavioral flexibility (e.g., Borg et al., 2009; Jedema et al., 2009) by such a mechanism, it may have less of a role when a subject has to deal with a myriad of stimuli. However, the 5-HT system is known to be involved in the emotional response to aversive events (Cools et al., 2008). As both the IGT and RGTs require subjects to integrate multiple stimuli (e.g., reward magnitude, probability of reward, punishment duration), 5-HT may play a large role in incorporation the concept of loss, and further research should be conducted to determine the role of acute and chronic manipulations of 5-HT.

\section{LIMITATIONS AND PITFALLS OF THE RGTS}

All of the RGT models capture one or more features of the human IGT, and have been validated to varying degrees. However, each of the RGTs also has limitations, and no single task fully captures all factors present in the IGT. If these limitations are taken into account when interpreting the data, the rodent models show great promise in being able to address research questions that cannot be easily studied in humans.

One general limitation of all RGTs is that rewards are represented by food pellets - a primary reinforcer - rather than a secondary reinforcer akin to money in the IGT. Given that rodents foraging for food in uncertain environments and human behavior in decision-making tasks share several features, it could be argued that the use of food as a reward may add to the ethological validity of the tasks. Moreover, utilizing food pellets presents some practical advantages in comparison to other types of rewards, such as the possibility of precise magnitude quantification, easiness in administration, and low impact on general psychological/physical functions (in contrast with psychoactive drugs, such as amphetamine, which mimic the effects of primary reinforcers at central level but also produce major side effects, e.g., the emergence of hyperactivity). However, the incentive value of food reward normally depends on an animal's motivational state (hunger/satiety; Cardinal et al., 2002). Therefore, interpretation of choice behavior in RGT models may be confounded by this highly uncontrollable factor. Although manipulation of the animals' drive for food through the employment of different food deprivation levels has been found to have no impact on decision-making in the RGT $_{\text {one session reward and time-out }}$ model (Rivalan et al., 2009a), this has yet to be determined for the other RGT versions. On the other hand, the incentive value of money, as used in human IGTs (see below) is also subjective to individual differences in money-triggered incentive salience, therefore this may be less of a concern.

By far the biggest concern with using food pellets as rewards relates to the accuracy of any of the RGTs to model the concept of loss. In the IGT, subjects materially experience financial "wins" and "losses" every time a selection is made. The probability associated 
with each trial of incurring financial penalties appears to be central for IGT performance (Fernie and Tunney, 2006): for instance, a high frequency of losses can lead human subjects to discard decks that are advantageous in the long-term (Chiu et al., 2008; Lin et al., 2009). Given that sugar pellets are instantly consumed, rather than accumulated over time and then eaten, it is impossible to take sugar pellets away from animals once they have been won, i.e., truly reproducing the sensation of loss. As iterated above, in order to model the concept of loss in the RGTs, punishment is accomplished by delivery of quinine-treated instead of normal food items ( $\left.\mathrm{RGT}_{\text {reward or quinine }}\right)$, the absence of reward ( $\left.\mathrm{RGT}_{\text {reward probabilities }}\right)$, or delays ( $\mathrm{RGT}_{\text {one session reward and time-out }}$ and $\left.\mathrm{RGT}_{\text {reward or time-out }}\right)$. In all cases except for $\mathrm{RGT}_{\text {reward probabilities, an actual decrease of }}$ a positive reinforcer is achieved, since choosing disadvantageous options has a negative impact on the total amount of food pellets consumed during the test. Nevertheless, employing unpalatable food or delays cannot reproduce an absolute resource deficit as a final outcome.

Gain/loss frequencies associated with each response option can be an important determinant of choice behavior during the IGT (Chiu et al., 2008; Lin et al., 2009). Regarding this task variable in the RGT models here examined, a number of discrepancies with the original human task can be identified. For both the $\mathrm{RGT}_{\text {reward or quinine }}$ and $\mathrm{RGT}_{\text {reward or time-out }}$ models, the disadvantageous options are associated with large but less frequent immediate rewards but larger more frequent punishments, while the advantageous options are associated with more frequent, although smaller, gains and infrequent but smaller losses. In contrast, within the IGT, the frequency of punishment delivery is varied within advantageous and disadvantageous options, but does not vary between them, such that there is both an advantageous and disadvantageous options associated with a high and low frequency of punishment; the only variable that differs is the size of the respective rewards and punishments. From this perspective, the RGT model which best captures the reinforcement contingencies

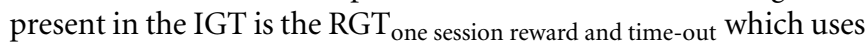
two reward sizes ( 1 vs. 2 pellets) and two probabilities of a penalty $(0.5$ and 0.25$)$. This task would therefore be most appropriate for the investigation of the "prominent deck B" phenomenon, in which individuals find it difficult to avoid responding at the high reward deck associated with the lowest probability of punishment. However, it could be argued the probability of receiving a penalty in this RGT version is still higher than that in the IGT ( 0.4 and 0.1 for decks A and B respectively).

The fact that the reinforcement contingencies in the RGT models are not exactly the same as the IGT may offer some unexpected benefits. For example, in the $\mathrm{RGT}_{\text {reward or time-out }}$ model, one of the more advantageous options (P1) involves a higher frequency of wins and shorter punishing time-out periods than the most optimal strategy (P2). Choice of $\mathrm{P} 1$ yields more reward than the "high risk-high reward" options (P3/P4) and certainly does not represent a "risky" choice, but is nonetheless suboptimal and may reflect riskaverse/overtly loss-sensitive decision-making. There is no such component in the IGT, but it may be of interest nonetheless. Likewise, the fact that rats in the $\mathrm{RGT}_{\text {reward probabilities }}$ model prefer the safe option even though there is only a marginal difference in net gain between the risky and advantageous options, may likewise be informative when considering decision-making biases under uncertainty.

It can be argued for both human and rodent IGT that subjects may perform worse as a result of working memory deficits and therefore have problems incorporating previous outcomes in their subsequent choices. Indeed, humans with impaired working memory were found to perform worse on the IGT (Bechara et al., 1998; Suhr and Hammers, 2010). Furthermore, discrimination learning, reversal learning and attentional capacities, punishment and reward sensitivity may all affect performance but are difficult to dissect within the IGT. In rodents, specific tasks have been widely employed to address these processes and may be combined with RGT to elucidate how different learning and decision-processes are interweaved in a complex decision-making task like the IGT.

\section{CONCLUSION}

Poor decision-making is a core deficit of major psychiatric disorders, and the identification of the underlying neural mechanisms will importantly advance both the diagnosis and treatment of these disorders. Animal models of affective decision-making provide an important tool in achieving this goal. In this review we discussed four RGTs that model specific aspects of the human IGT. In all these tests animals appear to use strategies that resemble those used by humans. That is, initially the animals explore the different choice options, but thereafter show a consistent behavioral pattern in which they attain to a given strategy. Lesion and immunohistochemistry studies have thus far shown that RGT performance is modulated by a similar neural circuitry as in humans, involving parts of the PFC, the nucleus accumbens, and BLA. Factors like the perceived value of the wins and losses, probability and time, and the integration of this information by neuromodulators dopamine and serotonin play an important role in guiding choice.

Because carefully controlled longitudinal studies in humans are hampered by practical issues, the RGTs provide new opportunities to investigate to what extent pre-existing changes in decision-making predict the development and treatment outcome of psychopathologies under influence of genes, stress, or the availability of drugs of abuse (Potenza, 2009). Although prevention is hard to achieve, even when risk factors have been identified, improvements in diagnosis may aid in the design of individualized therapies. Obviously, much remains to be done before we are able to use RGTs for this purpose, but the growing interest, and concomitantly, the development and validation of RGTs, provide heuristically useful data. While the available RGTs need further validation, one option that should be considered is whether the different RGTs should be used in parallel, or integrated into a more uniform model to investigate the factors and mechanisms associated with impaired decision-making. One potential advantage to maintaining the different models is that they all have distinct strengths. Together, comparisons between results obtain in the different RGTs are expected to provide significant contributions to our understanding of a broad range of neuropsychiatric illnesses, which will be of great benefit to society. 


\section{REFERENCES}

Apkarian, A. V., Sosa, Y., Krauss, B. R., Thomas, P. S., Fredrickson, B. E., Levy, R. E., Harden, R. N., and Chialvo, D. R. (2004). Chronic pain patients are impaired on an emotional decision-making task. Pain 108, 129-136.

Balleine, B. W., and O'Doherty, J. P. (2010). Human and rodent homologies in action control: corticostriatal determinants of goal-directed and habitual action. Neuropsychopharmacology 35, 48-69.

Barbas, H. (2000). Connections underlying the synthesis of cognition, memory, and emotion in primate prefrontal cortices. Brain Res. Bull. 52, 319-330.

Bark, R., Dieckmann, S., Bogerts, B., and Northoff, G. (2005). Deficit in decision making in catatonic schizophrenia: an exploratory study. Psychiatry Res. 134, 131-141.

Bechara, A. (2001). Neurobiology of decision-making: risk and reward. Semin. Clin. Neuropsychiatry 6, 205-216.

Bechara, A., Damasio, A. R., Damasio, H., and Anderson, S. W. (1994). Insensitivity to future consequences following damage to human prefrontal cortex. Cognition 50, 7-15.

Bechara, A., and Damasio, H. (2002). Decision-making and addiction (part I): impaired activation of somatic states in substance dependent individuals when pondering decisions with negative future consequences. Neuropsychologia 40, 1675-1689.

Bechara, A., Damasio, H., Damasio, A. R., and Lee, G. P. (1999). Different contributions of the human amygdala and ventromedial prefrontal cortex to decision-making. J. Neurosci. 19, 5473-5481.

Bechara, A., Damasio, H., Tranel, D., and Anderson, S. W. (1998). Dissociation of working memory from decision making within the human prefrontal cortex. J. Neurosci. 18, 428-437.

Bechara, A., Damasio, H., Tranel, D., and Damasio, A. R. (1997). Deciding advantageously before knowing the advantageous strategy. Science 275, 1293-1295.

Bechara, A., Damasio, H., Tranel, D., and Damasio, A. R. (2005). The Iowa Gambling Task and the somatic marker hypothesis: some questions and answers. Trends Cogn. Sci. (Regul. Ed.) 9, 159-162; discussion 162-154.

Bechara, A., Dolan, S., Denburg, N., Hindes, A., Anderson, S. W., and Nathan, P. E. (2001). Decision-making deficits, linked to a dysfunctional ventromedial prefrontal cortex, revealed in alcohol and stimulant abusers. Neuropsychologia 39, 376-389.

Bechara, A., Dolan, S., and Hindes, A. (2002). Decision-making and addiction (part II): myopia for the future or hypersensitivity to reward? $\mathrm{Neu}$ ropsychologia 40, 1690-1705.

Bechara, A., and Martin, E. M. (2004). Impaired decision making related to working memory deficits in individuals with substance addictions. Neuropsychology 18, 152-162.

Bechara, A., Tranel, D., and Damasio, H. (2000). Characterization of the decision-making deficit of patients with ventromedial prefrontal cortex lesions. Brain $123(\mathrm{Pt}$ 11), 2189-2202.

Bechara, A., Tranel, D., Damasio, H., and Damasio, A. R. (1996). Failure to respond autonomically to anticipated future outcomes following damage to prefrontal cortex. Cereb. Cortex 6, 215-225.

Bolla, K. I., Eldreth, D. A., Matochik, J. A., and Cadet, J. L. (2004). Sexrelated differences in a gambling task and its neurological correlates. Cereb. Cortex 14, 1226-1232.

Borg, J., Henningsson, S., Saijo, T., Inoue, M., Bah, J., Westberg, L., Lundberg, J., Jovanovic, H., Andree, B., Nordstrom, A. L., Halldin, C., Eriksson, E., and Farde, L. (2009). Serotonin transporter genotype is associated with cognitive performance but not regional 5HT1A receptor binding in humans. Int. J. Neuropsychopharmacol. 12, 783-792.

Branchi, I. (2010). The double edged sword of neural plasticity: increasing serotonin levels leads to both greater vulnerability to depression and improved capacity to recover. Psychoneuroendocrinology 36, 339-351.

Brand, M., Grabenhorst, F., Starcke, K., Vandekerckhove, M. M., and Markowitsch, H. J. (2007a). Role of the amygdala in decisions under ambiguity and decisions under risk: evidence from patients with UrbachWiethe disease. Neuropsychologia 45, 1305-1317.

Brand, M., Recknor, E. C., Grabenhorst, F., and Bechara, A. (2007b). Decisions under ambiguity and decisions under risk: correlations with executive functions and comparisons of two different gambling tasks with implicit and explicit rules. J. Clin. Exp. Neuropsychol. 29, 86-99.

Brand, M., Kalbe, E., Labudda, K., Fujiwara, E., Kessler, J., and Markowitsch, H. J. (2005). Decision-making impairments in patients with pathological gambling. Psychiatry Res. 133, 91-99.

Brand, M., Labudda, K., Kalbe, E., Hilker, R., Emmans, D., Fuchs, G.,
Kessler, J., and Markowitsch, H. J. (2004). Decision-making impairments in patients with Parkinson's disease. Behav. Neurol. 15, 77-85.

Brody, A. L., Mandelkern, M. A., Olmstead, R. E., Scheibal, D., Hahn, E., Shiraga, S., Zamora-Paja, E., Farahi, J., Saxena, S., London, E. D., and Mccracken, J. T. (2006). Gene variants of brain dopamine pathways and smokinginduced dopamine release in the ventral caudate/nucleus accumbens. Arch. Gen. Psychiatry 63, 808-816.

Brogan, A., Hevey, D., and Pignatti, R. (2010). Anorexia, bulimia, and obesity: shared decision making deficits on the Iowa gambling task (IGT). J. Int. Neuropsychol. Soc. 16, 711-715.

Brown, T. A., and Barlow, D. H. (2005). Dimensional versus categorical classification of mental disorders in the fifth edition of the Diagnostic and Statistical Manual of Mental Disorders and beyond: comment on the special section. J. Abnorm. Psychol. 114, 551-556.

Brown, V. J., and Bowman, E. M. (2002). Rodent models of prefrontal cortical function. Trends Neurosci. 25, 340-343.

Bush, G., Luu, P., and Posner, M. I. (2000). Cognitive and emotional influences in anterior cingulate cortex. Trends Cogn. Sci. (Regul. Ed.) 4 , 215-222.

Campbell-Meiklejohn, D. K., Woolrich, M. W., Passingham, R. E., and Rogers, R. D. (2008). Knowing when to stop: the brain mechanisms of chasing losses. Biol. Psychiatry 63, 293-300.

Canli, T., Qiu, M., Omura, K., Congdon, E., Haas, B. W., Amin, Z., Herrmann, M. J., Constable, R. T., and Lesch, K. P. (2006). Neural correlates of epigenesis. Proc. Natl. Acad. Sci. U.S.A. 103, 16033-16038.

Cardinal, R. N., Parkinson, J. A., Hall, J., and Everitt, B. J. (2002). Emotion and motivation: the role of the amygdala, ventral striatum, and prefrontal cortex. Neurosci. Biobehav. Rev. 26, 321-352.

Cardinal, R. N., Pennicott, D. R., Sugathapala, C. L., Robbins, T. W., and Everitt, B. J. (2001). Impulsive choice induced in rats by lesions of the nucleus accumbens core. Science 292, 2499-2501.

Cavedini, P., Bassi, T., Ubbiali, A., Casolari, A., Giordani, S., Zorzi, C., and Bellodi, L. (2004). Neuropsychological investigation of decision-making in anorexia nervosa. Psychiatry Res. 127, 259-266.

Cavedini, P., Riboldi, G., D’annucci, A., Belotti, P., Cisima, M., and Bellodi, L. (2002a). Decision-making heterogeneity in obsessive-compulsive disorder: ventromedial prefrontal cortex function predicts different treatment outcomes. Neuropsychologia 40, 205-211.

Cavedini, P., Riboldi, G., Keller, R., D'annucci, A., and Bellodi, L. (2002b). Frontal lobe dysfunction in pathological gambling patients. Biol. Psychiatry 51, 334-341.

Cavedini, P., Zorzi, C., Piccinni, M., Cavallini, M. C., and Bellodi, L. (2010). Executive dysfunctions in obsessivecompulsive patients and unaffected relatives: searching for a new intermediate phenotype. Biol. Psychiatry $67,1178-1184$.

Chen, X., Wang, X., O'neill, A. F., Walsh, D., and Kendler, K. S. (2004). Variants in the catecholo-methyltransferase (COMT) gene are associated with schizophrenia in Irish high-density families. Mol. Psychiatry 9, 962-967.

Chiu, Y. C., Lin, C. H., Huang, J. T., Lin, S., Lee, P. L., and Hsieh, J. C. (2008). Immediate gain is long-term loss: are there foresighted decision makers in the Iowa gambling task? Behav. Brain Funct. 4, 13.

Christakou, A., Robbins, T. W., and Everitt, B. J. (2004). Prefrontal cortical-ventral striatal interactions involved in affective modulation of attentional performance: implications for corticostriatal circuit function. J. Neurosci. 24, 773-780.

Clark, L., Bechara, A., Damasio, H., Aitken, M. R., Sahakian, B. J., and Robbins, T. W. (2008). Differential effects of insular and ventromedial prefrontal cortex lesions on risky decision-making. Brain 131, 1311-1322.

Clark, L., Manes, F., Antoun, N., Sahakian, B. J., and Robbins, T. W. (2003). The contributions of lesion laterality and lesion volume to decision-making impairment following frontal lobe damage. $\mathrm{Neu}$ ropsychologia 41, 1474-1483.

Comings, D. E., Rosenthal, R. J., Lesieur, H. R., Rugle, L. J., Muhleman, D., Chiu, C., Dietz, G., and Gade, R. (1996). A study of the dopamine D2 receptor gene in pathological gambling. Pharmacogenetics 6, 223-234.

Cools, R., Roberts, A. C., and Robbins, T. W. (2008). Serotonergic regulation of emotional and behavioural control processes. Trends Cogn. Sci. (Regul. Ed.) 12, 31-40.

Crone, E. A., and van der Molen, M. W. (2004). Developmental changes in real life decision making: performance on a gambling task previously shown to depend on the ventromedial prefrontal cortex. Dev. Neuropsychol. 25, 251-279. 
da Rocha, F. F., Malloy-Diniz, L., Lage, N. V., Romano-Silva, M. A., De Marco, L. A., and Correa, H. (2008). Decision-making impairment is related to serotonin transporter promoter polymorphism in a sample of patients with obsessivecompulsive disorder. Behav. Brain Res. 195, 159-163.

Davis, J. F., Loos, M., Di Sebastiano, A. R., Brown, J. L., Lehman, M. N., and Coolen, L. M. (2010). Lesions of the medial prefrontal cortex cause maladaptive sexual behavior in male rats. Biol. Psychiatry 67, 1199-1204.

Davis, K. P., Tweed, S., and Curtis, C. (2007). Personality traits associated with decision-making deficits. Pers. Individ. Dif. 42, 279-290.

de Visser, L., Baars, A. M., van't Klooster, J., and van den Bos, R. (2011a). Transient inactivation of the medial prefrontal cortex affects both anxiety and decision-making in male wistar rats. Front. Neurosci. 5:102. doi: 10.3389/fnins.2011.00102

de Visser, L., Baars, A. M., Lavrijsen, M., Van Der Weerd, C. M., and Van Den Bos, R. (2011b). Decision-making performance is related to levels of anxiety and differential recruitment of frontostriatal areas in male rats. Neuroscience 184, 97-106.

de Visser, L., Van Der Knaap, L. J., Van De Loo, A. J., Van Der Weerd, C. M., Ohl, F., and Van Den Bos, R. (2010). Trait anxiety affects decision-making differently in healthy men and women: towards gender-specific endophenotypes of anxiety. Neuropsychologia 48, 1598-1606.

Dellu, F., Mayo, W., Piazza, P. V., Le Moal, M., and Simon, H. (1993). Individual differences in behavioral responses to novelty in rats. Possible relationship with the sensationseeking trait in man. Pers. Individ. Dif. 14, 411-418.

Dellu, F., Piazza, P. V., Mayo, W., Le Moal, M., and Simon, H. (1996). Novelty-seeking in rats - biobehavioral characteristics and possible relationship with the sensationseeking trait in man. Neuropsychobiology 34, 136-145.

Di Chiara, G., and Bassareo, V. (2007). Reward system and addiction: what dopamine does and doesn't do. Curr. Opin. Pharmacol. 7, 69-76.

Dias, R., Robbins, T. W., and Roberts, A. C. (1996). Primate analogue of the Wisconsin card sorting test: effects of excitotoxic lesions of the prefrontal cortex in the marmoset. Behav. Neurosci. 110, 872-886.

Dom, G., De Wilde, B., Hulstijn, W., Van Den Brink, W., and Sabbe,
B. (2006). Decision-making deficits in alcohol-dependent patients with and without comorbid personality disorder. Alcohol. Clin. Exp. Res. 30, 1670-1677.

Drechsler, R., Rizzo, P., and Steinhausen, H. C. (2008). Decision-making on an explicit risk-taking task in preadolescents with attentiondeficit/hyperactivity disorder. J. Neural Transm. 115, 201-209.

Dunn, B. D., Dalgleish, T., and Lawrence, A. D. (2006). The somatic marker hypothesis: a critical evaluation. Neurosci. Biobehav. Rev. 30, 239-271.

Ebstein, R. P. (2006). The molecular genetic architecture of human personality: beyond self-report questionnaires. Mol. Psychiatry 11, 427-445.

Elliott, R., Dolan, R. J., and Frith, C. D. (2000). Dissociable functions in the medial and lateral orbitofrontal cortex: evidence from human neuroimaging studies. Cereb. Cortex 10, 308-317.

Ernst, M., Bolla, K., Mouratidis, M., Contoreggi, C., Matochik, J. A., Kurian, V., Cadet, J. L., Kimes, A. S., and London, E. D. (2002). Decisionmaking in a risk-taking task: a PET study. Neuropsychopharmacology 26, 682-691.

Ernst, M., Grant, S. J., London, E. D., Contoreggi, C. S., Kimes, A. S., and Spurgeon, L. (2003). Decision making in adolescents with behavior disorders and adults with substance abuse. Am. J. Psychiatry 160, 33-40.

Fellows, L. K., and Farah, M. J. (2005) Different underlying impairments in decision-making following ventromedial and dorsolateral frontal lobe damage in humans. Cereb. Cortex 15, 58-63.

Fernie, G., and Tunney, R. J. (2006). Some decks are better than others: the effect of reinforcer type and task instructions on learning in the Iowa gambling task. Brain Cogn. 60, 94-102.

Floresco, S. B., Ghods-Sharifi, S., Vexelman, C., and Magyar, O. (2006). Dissociable roles for the nucleus accumbens core and shell in regulating set shifting. J. Neurosci. 26, 2449-2457.

Frank, M. J., Doll, B. B., Oas-Terpstra, J., and Moreno, F. (2009). Prefrontal and striatal dopaminergic genes predict individual differences in exploration and exploitation. Nat. Neurosci. 12, 1062-1068.

Franken, I. H., Van Strien, J. W., Nijs, I., and Muris, P. (2008). Impulsivity is associated with behavioral decision-making deficits. Psychiatry Res. 158, 155-163.

Fukui, H., Murai, T., Fukuyama, H., Hayashi, T., and Hanakawa, T. (2005). Functional activity related to risk anticipation during performance of the Iowa gambling task. Neuroimage 24, 253-259.

Garon, N., Moore, C., and Waschbusch, D. A. (2006). Decision making in children with ADHD only, ADHDanxious/depressed, and control children using a child version of the Iowa gambling task. J. Atten. Disord. 9, 607-619.

Gijsman, H. J., Scarna, A., Harmer, C. J., Mctavish, S. B., Odontiadis, J., Cowen, P. J., and Goodwin, G. M. (2002). A dose-finding study on the effects of branch chain amino acids on surrogate markers of brain dopamine function. Psychopharmacology (Berl.) 160, 192-197.

Glicksohn, J., Naor-Ziv, R., and Leshem, R. (2007). Impulsive decisionmaking: learning to gamble wisely? Cognition 105, 195-205.

Glimcher, P. W., Camerer, C. F., Fehr, E., and Poldrack, R. A. (2009). Neuroeconomics Decision Making and the Brain. London: Academic press.

Goudriaan, A. E., Oosterlaan, J., De Beurs, E., and Van Den Brink, W. (2005). Decision making in pathological gambling: a comparison between pathological gamblers, alcohol dependents, persons with Tourette syndrome, and normal controls. Brain Res. Cogn. Brain Res. 23, 137-151.

Goudriaan, A. E., Oosterlaan, J., De Beurs, E., and Van Den Brink, W. (2006). Neurocognitive functions in pathological gambling: a comparison with alcohol dependence, Tourette syndrome and normal controls. Addiction 101, 534-547.

Grant, S., Contoreggi, C., and London, E. D. (2000). Drug abusers show impaired performance in a laboratory test of decision making. $\mathrm{Neu}$ ropsychologia 38, 1180-1187.

Greenwood, T. A., Alexander, M., Keck, P. E., Mcelroy, S., Sadovnick, A. D., Remick, R. A., and Kelsoe, J. R. (2001). Evidence for linkage disequilibrium between the dopamine transporter and bipolar disorder. Am. J. Med. Genet. 105, 145-151.

Greenwood, T. A., Schork, N. J., Eskin, E., and Kelsoe, J. R. (2006). Identification of additional variants within the human dopamine transporter gene provides further evidence for an association with bipolar disorder in two independent samples. Mol. Psychiatry 11, 125-133, 115.
Ha, R. Y., Namkoong, K., Kang, J. I., Kim, Y. T., and Kim, S. J. (2009). Interaction between serotonin transporter promoter and dopamine receptor D4 polymorphisms on decision making. Prog. Neuropsychopharmacol. Biol. Psychiatry 33, 1217-1222.

Hamarman, S., Fossella, J., Ulger, C., Brimacombe, M., and Dermody, J. (2004). Dopamine receptor 4 (DRD4) 7-repeat allele predicts methylphenidate dose response in children with attention deficit hyperactivity disorder: a pharmacogenetic study. J. Child Adolesc. Psychopharmacol. 14, 564-574.

Hanson, K. L., Luciana, M., and Sullwold, K. (2008). Reward-related decision-making deficits and elevated impulsivity among MDMA and other drug users. Drug Alcohol Depend. 96, 99-110.

Hariri, A. R., Mattay, V. S., Tessitore, A., Kolachana, B., Fera, F., Goldman, D., Egan, M. F., and Weinberger, D. R. (2002). Serotonin transporter genetic variation and the response of the human amygdala. Science 297, 400-403.

Harmer, C. J., Mctavish, S. F., Clark, L., Goodwin, G. M., and Cowen, P. J. (2001). Tyrosine depletion attenuates dopamine function in healthy volunteers. Psychopharmacology (Berl.) 154, 105-111.

Hayton, S., and Olmstead, M. (2009). "Fractionating animal models of motor impulsivity: reconciling the neurochemistry of disinhibition," in Endophenotypes of Psychiatric and Neurodegenerative Disorders in Rodent Models, ed. S. Granon (Kerala: Transworld Research Network), 135-158.

He, Q., Xue, G., Chen, C., Lu, Z., Dong, Q., Lei, X., Ding, N., Li, J., Li, H., Chen, C., Li, J., Moyzis, R. K., and Bechara, A. (2010). Serotonin transporter gene-linked polymorphic region (5-HTTLPR) influences decision making under ambiguity and risk in a large Chinese sample. Neuropharmacology 59, 518-526.

Heinz, A., Braus, D. F., Smolka, M. N., Wrase, J., Puls, I., Hermann, D., Klein, S., Grusser, S. M., Flor, H., Schumann, G., Mann, K., and Buchel, C. (2005). Amygdalaprefrontal coupling depends on a genetic variation of the serotonin transporter. Nat. Neurosci. 8 , 20-21.

Homberg, J. R., and Lesch, K. P. (2010). Looking on the bright side of serotonin transporter gene variation. Biol. Psychiatry 69, 513-519. 
Homberg, J. R., Pattij, T., Janssen, M. C., Ronken, E., De Boer, S. F., Schoffelmeer, A. N., and Cuppen, E. (2007). Serotonin transporter deficiency in rats improves inhibitory control but not behavioural flexibility. Eur. J. Neurosci. 26, 2066-2073.

Homberg, J. R., Van Den Bos, R., Den Heijer, E., Suer, R., and Cuppen, E. (2008). Serotonin transporter dosage modulates long-term decision-making in rat and human. Neuropharmacology 55, 80-84.

Horschitz, S., Hummerich, R., Lau, T., Rietschel, M., and Schloss, P. (2005). A dopamine transporter mutation associated with bipolar affective disorder causes inhibition of transporter cell surface expression. Mol. Psychiatry 10, 1104-1109.

Hsu, M., Bhatt, M., Adolphs, R., Tranel, D., and Camerer, C. F. (2005). Neural systems responding to degrees of uncertainty in human decisionmaking. Science 310, 1680-1683.

Hutchison, K. E., Wooden, A., Swift, R. M., Smolen, A., Mcgeary, J., Adler, L., and Paris, L. (2003). Olanzapine reduces craving for alcohol: a DRD4 VNTR polymorphism by pharmacotherapy interaction. Neuropsychopharmacology 28, 1882-1888.

Hyafil, A., Summerfield, C., and Koechlin, E. (2009). Two mechanisms for task switching in the prefrontal cortex. J. Neurosci. 29, 5135-5142.

Jedema, H. P., Gianaros, P. J., Greer, P. J., Kerr, D. D., Liu, S., Higley, J. D., Suomi, S. J., Olsen, A. S., Porter, J. N., Lopresti, B. J., Hariri, A. R., and Bradberry, C. W. (2009). Cognitive impact of genetic variation of the serotonin transporter in primates is associated with differences in brain morphology rather than serotonin neurotransmission. Mol. Psychiatry $15,512-522,446$.

Ji, G., Sun, H., Fu, Y., Li, Z., Pais-Vieira, M., Galhardo, V., and Neugebauer, V. (2010). Cognitive impairment in pain through amygdala-driven prefrontal cortical deactivation. J. Neurosci. 30, 5451-5464.

Jollant, F., Buresi, C., Guillaume, S., Jaussent, I., Bellivier, F., Leboyer, M., Castelnau, D., Malafosse, A., and Courtet, P. (2007). The influence of four serotonin-related genes on decision-making in suicide attempters. Am. J. Med. Genet. B Neuropsychiatr. Genet. 144B, 615-624.

Juhasz, G., Downey, D., Hinvest, N., Thomas, E., Chase, D., Toth, Z. G., Lloyd-Williams, K., Mekli, K., Platt, H., Payton, A., Bagdy, G., Elliott, R., Deakin, J. F., and Anderson, I. M. (2010). Risk-taking behavior in a gambling task associated with variations in the tryptophan hydroxylase 2 gene: relevance to psychiatric disorders. Neuropsychopharmacology 35, 1109-1119.

Kahneman, D., and Tversky, A. (1979). Prospect theory: an analysis of decision under risk. Econometrica 47, 263-291.

Kalueff, A. V., Olivier, J. D., Nonkes, L. J., and Homberg, J. R. (2009). Conserved role for the serotonin transporter gene in rat and mouse neurobehavioral endophenotypes. Neurosci. Biobehav. Rev. 34, 373-386.

Kang, J. I., Namkoong, K., Ha, R. Y., Jhung, K., Kim, Y. T., and Kim, S. J. (2010). Influence of BDNF and COMT polymorphisms on emotional decision making. Neuropharmacology 58, 1109-1113.

Kathleen Holmes, M., Bearden, C. E., Barguil, M., Fonseca, M., Serap Monkul, E., Nery, F. G., Soares, J. C., Mintz, J., and Glahn, D. C. (2009). Conceptualizing impulsivity and risk taking in bipolar disorder: importance of history of alcohol abuse. Bipolar Disord. 11, 33-40.

Kazama, A., and Bachevalier, J. (2009). Selective aspiration or neurotoxic lesions of orbital frontal areas 11 and 13 spared monkeys' performance on the object discrimination reversal task. J. Neurosci. 29, 2794-2804.

Kelsoe, J. R., Sadovnick, A. D., Kristbjarnarson, H., Bergesch, P., Mroczkowski-Parker, Z., Drennan, M., Rapaport, M. H., Flodman, P., Spence, M. A., and Remick, R. A. (1996). Possible locus for bipolar disorder near the dopamine transporter on chromosome 5. Am. J. Med. Genet. 67, 533-540.

Kennerley, S. W., Walton, M. E., Behrens, T. E., Buckley, M. J., and Rushworth, M. F. (2006). Optimal decision making and the anterior cingulate cortex. Nat. Neurosci. 9, 940-947.

Kester, H. M., Sevy, S., Yechiam, E., Burdick, K. E., Cervellione, K. L., and Kumra, S. (2006). Decision-making impairments in adolescents with early-onset schizophrenia. Schizophr. Res. 85, 113-123.

Knutson, B., Fong, G. W., Adams, C. M., Varner, J. L., and Hommer, D. (2001). Dissociation of reward anticipation and outcome with event-related fMRI. Neuroreport 12, 3683-3687.

Kobayakawa, M., Tsuruya, N., and Kawamura, M. (2010). Sensitivity to reward and punishment in Parkinson's disease: an analysis of behavioral patterns (using) a modified version of the Iowa gambling task. Parkinsonism Relat. Disord. 16, 453-457.

Koot, S., Adriani, W., Saso, L., Bos van den, R., and Laviola, G. (2009).
Home cage testing of delay discounting in rats. Behav. Res. Methods 41, 1169-1176.

Koot, S., Bos van den, R., Adriani, W. and Laviola, G. (2010). "Home-cage testing of decision-making," in Proceedings of Measuring Behavior 2010, eds A. J. Spink, F. Grieco, O. E. Krips, L. W. S. Loijens, L. P. J. J. Noldus, and P. H. Zimmerman (Eindhoven), 145-148.

Krugel, L. K., Biele, G., Mohr, P. N., Li, S. C., and Heekeren, H. R. (2009). Genetic variation in dopaminergic neuromodulation influences the ability to rapidly and flexibly adapt decisions. Proc. Natl. Acad. Sci. U.S.A. 106, 17951-17956.

Kuhnen, C. M., and Chiao, J. Y. (2009). Genetic determinants of financial risk taking. PLoS ONE 4, e4362. doi:10.1371/journal.pone.0004362

Kuhnen, C. M., and Knutson, B. (2005). The neural basis of financial risk taking. Neuron 47, 763-770.

Lage, G. M., Malloy-Diniz, L. F., Matos, L. O., Bastos, M. A., Abrantes, S. S., and Correa, H. (2011). Impulsivity and the 5-HTTLPR polymorphism in a non-clinical sample. PLoS One 6, e16927.

Lawrence, N. S., Jollant, F., O'daly, O., Zelaya, F., and Phillips, M. L. (2009). Distinct roles of prefrontal cortical subregions in the Iowa gambling task. Cereb. Cortex 19, 1134-1143.

Lawrence, N. S., Wooderson, S., MataixCols, D., David, R., Speckens, A., and Phillips, M. L. (2006). Decision making and set shifting impairments are associated with distinct symptom dimensions in obsessivecompulsive disorder. Neuropsychology 20, 409-419.

Lee, D., Rushworth, M. F., Walton, M. E., Watanabe, M., and Sakagami, M. (2007a). Functional specialization of the primate frontal cortex during decision making. J. Neurosci. 27, 8170-8173.

Lee, Y., Kim, Y. T., Seo, E., Park, O., Jeong, S. H., Kim, S. H., and Lee, S. J. (2007b). Dissociation of emotional decision-making from cognitive decision-making in chronic schizophrenia. Psychiatry Res. 152, 113-120.

Lesch, K. P., Bengel, D., Heils, A., Sabol, S. Z., Greenberg, B. D., Petri, S., Benjamin, J., Muller, C. R., Hamer, D. H., and Murphy, D. L. (1996). Association of anxietyrelated traits with a polymorphism in the serotonin transporter gene regulatory region. Science 274, 1527-1531.

Liao, P. C., Uher, R., Lawrence, N., Treasure, J., Schmidt, U., Campbell, I.
C., Collier, D. A., and Tchanturia, K. (2009). An examination of decision making in bulimia nervosa. J. Clin. Exp. Neuropsychol. 31, 455-461.

Lin, C. H., Chiu, Y. C., Cheng, C. M., and Hsieh, J. C. (2008). Brain maps of Iowa gambling task. BMC Neurosci. 9, 72. doi:10.1186/1471-2202-9-72

Lin, C. H., Chiu, Y. C., and Huang, J. T. (2009). Gain-loss frequency and final outcome in the Soochow gambling task: a reassessment. Behav. Brain Funct. 5, 45.

Linnet, J., Moller, A., Peterson, E., Gjedde, A., and Doudet, D. (2010). Dopamine release in ventral striatum during Iowa gambling task performance is associated with increased excitement levels in pathological gambling. Addiction 106, 383-390.

Linnet, J., Moller, A., Peterson, E., Gjedde, A., and Doudet, D. (2011) Dopamine release in ventral striatum during Iowa gambling task performance is associated with increased excitement levels in pathological gambling. Addiction 106, 383-390.

Linnoila, M., Virkkunen, M., Scheinin, M., Nuutila, A. Rimon, R., and Goodwin, F. K. (1983). Low cerebrospinal fluid 5-hydroxyindoleacetic acid concentration differentiates impulsive from nonimpulsive violent behavior. Life Sci. 33, 2609-2614.

Lotta, T., Vidgren, J., Tilgmann, C., Ulmanen, I., Melen, K., Julkunen, I., and Taskinen, J. (1995). Kinetics of human soluble and membrane-bound catechol O-methyltransferase: a revised mechanism and description of the thermolabile variant of the enzyme. Biochemistry 34, 4202-4210.

Luman, M., Oosterlaan, J., Knol, D. L., and Sergeant, J. A. (2008). Decisionmaking in ADHD: sensitive to frequency but blind to the magnitude of penalty? J. Child Psychol. Psychiatry 49, 712-722.

Magno, E., Foxe, J. J., Molholm, S., Robertson, I. H., and Garavan, $\mathrm{H}$. (2006). The anterior cingulate and error avoidance. J. Neurosci. 26, 4769-4773.

Mainen, Z. F., and Kepecs, A. (2009). Neural representation of behavioral outcomes in the orbitofrontal cortex. Curr. Opin. Neurobiol. 19, 84-91.

Malloy-Diniz, L., Fuentes, D., Leite, W. B., Correa, H., and Bechara, A. (2007). Impulsive behavior in adults with attention deficit/hyperactivity disorder: characterization of attentional, motor and cognitive impulsiveness. J. Int. Neuropsychol. Soc. 13, 693-698. 
Manes, F., Sahakian, B., Clark, L., Rogers, R., Antoun, N., Aitken, M., and Robbins, T. (2002). Decisionmaking processes following damage to the prefrontal cortex. Brain 125, 624-639.

Mannisto, P. T., and Kaakkola, S. (1999). Catechol-O-methyltransferase (COMT): biochemistry, molecular biology, pharmacology, and clinical efficacy of the new selective COMT inhibitors. Pharmacol. Rev. 51, 593-628.

Marazziti, D., Golia, F., Picchetti, M., Pioli, E., Mannari, P., Lenzi, F., Conversano, C., Carmassi, C., Catena Dell'osso, M., Consoli, G., Baroni, S., Giannaccini, G., Zanda, G., and Dell'osso, L. (2008). Decreased density of the platelet serotonin transporter in pathological gamblers. Neuropsychobiology 57, 38-43.

Maurex, L., Zaboli, G., Wiens, S., Asberg, M., Leopardi, R., and Ohman, A. (2009). Emotionally controlled decision-making and a gene variant related to serotonin synthesis in women with borderline personality disorder. Scand. J. Psychol. 50, 5-10.

Mazas, C. A., Finn, P. R., and Steinmetz, J. E. (2000). Decision-making biases, antisocial personality, and earlyonset alcoholism. Alcohol. Clin. Exp. Res. 24, 1036-1040.

McAlonan, K., and Brown, V. J. (2003). Orbital prefrontal cortex mediates reversal learning and not attentional set shifting in the rat. Behav. Brain Res. 146, 97-103.

McClure, S. M., Laibson, D. I., Loewenstein, G., and Cohen, J. D. (2004). Separate neural systems value immediate and delayed monetary rewards. Science 306, 503-507.

McGough, J. J. (2005). Attentiondeficit/hyperactivity disorder pharmacogenomics. Biol. Psychiatry 57, 1367-1373.

McKinney, W. T. Jr., and Bunney, W. E. Jr. (1969). Animal model of depression. I. Review of evidence: implications for research. Arch. Gen. Psychiatry 21, 240-248.

Meck, W. H. (2006). Neuroanatomical localization of an internal clock: a functional link between mesolimbic, nigrostriatal, and mesocortical dopaminergic systems. Brain Res. 1109, 93-107.

Meyer, J. H., Houle, S., Sagrati, S., Carella, A., Hussey, D. F., Ginovart, N., Goulding, V., Kennedy, J., and Wilson, A. A. (2004). Brain serotonin transporter binding potential measured with carbon 11-labeled DASB positron emission tomography: effects of major depressive episodes and severity of dysfunctional attitudes. Arch. Gen. Psychiatry 61, 1271-1279.

Miller, E. K., and Cohen, J. D. (2001). An integrative theory of prefrontal cortex function. Annu. Rev. Neurosci. 24, 167-202.

Mimura, M., Oeda, R., and Kawamura, M. (2006). Impaired decisionmaking in Parkinson's disease. Parkinsonism Relat. Disord. 12, 169-175.

Miu, A. C., Heilman, R. M., and Houser, D. (2008). Anxiety impairs decision-making: psychophysiological evidence from an Iowa Gambling Task. Biol. Psychol. 77, 353-358.

Murphy, E. R., Robinson, E. S., Theobald, D. E., Dalley, J. W., and Robbins, T. W. (2008). Contrasting effects of selective lesions of nucleus accumbens core or shell on inhibitory control and amphetamine-induced impulsive behaviour. Eur. J. Neurosci. 28, 353-363.

Murray, E. A., O'doherty, J. P., and Schoenbaum, G. (2007). What we know and do not know about the functions of the orbitofrontal cortex after 20 years of cross-species studies. J. Neurosci. 27, 8166-8169.

Must, A., Juhász, A., Rimanóczy, Á., Szabó, Z., Kéri, S., and Janka, Z. (2007). Major depressive disorder, serotonin transporter, and personality traits: why patients use suboptimal decision-making strategies? J. Affect. Disord. 103, 273-276.

Must, A., Szabo, Z., Bodi, N., Szasz, A., Janka, Z., and Keri, S. (2006). Sensitivity to reward and punishment and the prefrontal cortex in major depression. J. Affect. Disord. 90, 209-215.

Nackley, A. G., Shabalina, S. A., Tchivileva, I. E., Satterfield, K., Korchynskyi, O., Makarov, S. S., Maixner, W., and Diatchenko, L. (2006). Human catechol-O-methyltransferase haplotypes modulate protein expression by altering mRNA secondary structure. Science 314, 1930-1933.

Oliveira, F. T., Mcdonald, J. J., and Goodman, D. (2007). Performance monitoring in the anterior cingulate is not all error related: expectancy deviation and the representation of action-outcome associations. J. Cogn. Neurosci. 19, 1994-2004.

Ongur, D., and Price, J. L. (2000). The organization of networks within the orbital and medial prefrontal cortex of rats, monkeys and humans. Cereb. Cortex 10, 206-219.

Pacheco, J., Beevers, C. G., Benavides, C., Mcgeary, J., Stice, E., and Schnyer, D. M. (2009). Frontal-limbic white matter pathway associations with the serotonin transporter gene promoter region (5-HTTLPR) polymorphism. J. Neurosci. 29, 6229-6233.

Pais-Vieira, M., Lima, D., and Galhardo, V. (2007). Orbitofrontal cortexr lesions disrupt risk assessment in a novel serial decisionmaking task for rats. Neuroscience 145, 225-231.

Pais-Vieira, M., Mendes-Pinto, M. M. Lima, D., and Galhardo, V. (2009). Cognitive impairment of prefrontaldependent decision-making in rats after the onset of chronic pain. Neuroscience 161, 671-679.

Pallanti, S., Bernardi, S., Quercioli, L., Decaria, C., and Hollander, E. (2006). Serotonin dysfunction in pathological gamblers: increased prolactin response to oral $\mathrm{m}$-CPP versus placebo. CNS Spectr. 11, 956-964.

Paloyelis, Y., Asherson, P., Mehta, M. A., Faraone, S. V., and Kuntsi, J. (2010). DAT1 and COMT effects on delay discounting and trait impulsivity in male adolescents with attention deficit/hyperactivity disorder and healthy controls. Neuropsychopharmacology 35, 2414-2426.

Pattij, T., and Vanderschuren, L. J. (2008). The neuropharmacology of impulsive behaviour. Trends Pharmacol. Sci. 29, 192-199.

Paus, T., Petrides, M., Evans, A. C. and Meyer, E. (1993). Role of the human anterior cingulate cortex in the control of oculomotor, manual, and speech responses: a positron emission tomography study. J. Neurophysiol. 70, 453-469.

Perry, W., Minassian, A., Paulus, M. P. Young, J. W., Kincaid, M. J., Ferguson, E. J., Henry, B. L., Zhuang, X., Masten, V. L., Sharp, R. F., and Geyer, M. A. (2009). A reverse-translational study of dysfunctional exploration in psychiatric disorders: from mice to men. Arch. Gen. Psychiatry 66, 1072-1080.

Pezawas, L., Meyer-Lindenberg, A., Drabant, E. M., Verchinski, B. A., Munoz, K. E., Kolachana, B. S., Egan, M. F., Mattay, V. S., Hariri, A. R., and Weinberger, D. R. (2005). 5-HTTLPR polymorphism impacts human cingulate-amygdala interactions: a genetic susceptibility mechanism for depression. Nat. Neurosci. 8, 828-834.

Potenza, M. N. (2009). The importance of animal models of decision making, gambling, and related behaviors: implications for translational research in addiction. Neuropsychopharmacology 34, 2623-2624.

Pothuizen, H. H., Jongen-Relo, A. L., Feldon, J., and Yee, B. K. (2005). Double dissociation of the effects of selective nucleus accumbens core and shell lesions on impulsivechoice behaviour and salience learning in rats. Eur. J. Neurosci. 22, 2605-2616

Quilodran, R., Rothe, M., and Procyk, E. (2008). Behavioral shifts and action valuation in the anterior cingulate cortex. Neuron 57, 314-325.

Quirk, G. J., Russo, G. K., Barron, J. L., and Lebron, K. (2000). The role of ventromedial prefrontal cortex in the recovery of extinguished fear. $J$. Neurosci. 20, 6225-6231.

Ragozzino, M. E. (2007). The contribution of the medial prefrontal cortex, orbitofrontal cortex, and dorsomedial striatum to behavioral flexibility. Ann. N. Y. Acad. Sci. 1121, 355-375.

Reavis, R., and Overman, W. H. (2001). Adult sex differences on a decisionmaking task previously shown to depend on the orbital prefrontal cortex. Behav. Neurosci. 115, 196-206.

Ridderinkhof, K. R., Ullsperger, M., Crone, E. A., and Nieuwenhuis, S. (2004). The role of the medial frontal cortex in cognitive control. Science 306, 443-447.

Rivalan, M., Ahmed, S. H., and DelluHagedorn, F. (2009a). Risk-prone individuals prefer the wrong options on a rat version of the Iowa gambling task. Biol. Psychiatry 66, 743-749.

Rivalan, M., Blondeau, C., and DelluHagedorn, F. (2009b). "Modeling symptoms of mental disorders using a dimensional approach in the rat," in Endophenotypes of Psychiatric and Neurodegenerative Disorders in Rodent Models, ed. S. Granon (Kerala: Transworld Research Network), 15-40.

Rivalan, M., Coutureau, E., Fitoussi, A., and Dellu-Hagedorn, F. (2011). Inter-individual decision-making differences in the effects of cingulate, orbitofrontal, and prelimbic cortex lesions in a rat gambling task. Front. Behav. Neurosci. 5:22. doi:10.3389/fnbeh.2011.00022

Robbins, T. W. (2002). The 5-choice serial reaction time task: behavioural pharmacology and functional neurochemistry. Psychopharmacology (Berl.) 163, 362-380.

Robbins, T. W., and Arnsten, A. F. (2009). The neuropsychopharmacology of fronto-executive function: monoaminergic modulation. Annu. Rev. Neurosci. 32, 267-287.

Rogers, R. D., Everitt, B. J., Baldacchino, A., Blackshaw, A. J., Swainson, R., Wynne, K., Baker, N. B., Hunter, J., Carthy, T., Booker, E., London, M., Deakin, J. F., Sahakian, B. J., and Robbins, T. W. (1999). Dissociable deficits in the decision-making 
cognition of chronic amphetamine abusers, opiate abusers, patients with focal damage to prefrontal cortex, and tryptophan-depleted normal volunteers: evidence for monoaminergic mechanisms. Neuropsychopharmacology 20, 322-339.

Rogers, R. D., Ramnani, N., Mackay, C., Wilson, J. L., Jezzard, P., Carter, C. S., and Smith, S. M. (2004). Distinct portions of anterior cingulate cortex and medial prefrontal cortex are activated by reward processing in separable phases of decision-making cognition. Biol. Psychiatry 55, 594-602.

Roitman, J. D., and Roitman, M. F. (2010). Risk-preference differentiates orbitofrontal cortex responses to freely chosen reward outcomes. Eur. J. Neurosci. 31, 1492-1500.

Rolls, E. T., and Grabenhorst, F. (2008). The orbitofrontal cortex and beyond: from affect to decisionmaking. Prog. Neurobiol. 86, 216-244.

Roussos, P., Giakoumaki, S. G., and Bitsios, P. (2009). Cognitive and emotional processing in high novelty seeking associated with the L-DRD4 genotype. Neuropsychologia 47, 1654-1659.

Roussos, P., Giakoumaki, S. G., Pavlakis, S., and Bitsios, P. (2008). Planning, decision-making and the COMT rs4818 polymorphism in healthy males. Neuropsychologia 46 , 757-763.

Rudebeck, P. H., and Murray, E. A. (2008). Amygdala and orbitofrontal cortex lesions differentially influence choices during object reversal learning. J. Neurosci. 28, 8338-8343.

Rudebeck, P. H., Walton, M. E., Smyth, A. N., Bannerman, D. M., and Rushworth, M. F. (2006). Separate neural pathways process different decision costs. Nat. Neurosci. 9, 1161-1168.

Sallet, J., Quilodran, R., Rothe, M., Vezoli, J., Joseph, J. P., and Procyk, E. (2007). Expectations, gains, and losses in the anterior cingulate cortex. Cogn. Affect. Behav. Neurosci. 7, 327-336.

Schoenbaum, G., Chiba, A. A., and Gallagher, M. (1998). Orbitofrontal cortex and basolateral amygdala encode expected outcomes during learning. Nat. Neurosci. 1, 155-159.

Schoenbaum, G., Nugent, S. L., Saddoris, M. P., and Setlow, B. (2002). Orbitofrontal lesions in rats impair reversal but not acquisition of go, no-go odor discriminations. Neuroreport 13, 885-890.

Schoenbaum, G., Roesch, M. R., Stalnaker, T. A., and Takahashi, Y. K. (2009). A new perspective on the role of the orbitofrontal cortex in adaptive behaviour. Nat. Rev. Neurosci. $10,885-892$.

Schoenbaum, G., Setlow, B., Saddoris, M. P., and Gallagher, M. (2003). Encoding predicted outcome and acquired value in orbitofrontal cortex during cue sampling depends upon input from basolateral amygdala. Neuron 39, 855-867.

Schultz, W. (2002). Getting formal with dopamine and reward. Neuron 36, 241-263.

Seamans, J. K., and Yang, C. R. (2004). The principal features and mechanisms of dopamine modulation in the prefrontal cortex. Prog. Neurobiol. 74, 1-58.

Seedat, S., Kesler, S., Niehaus, D. J., and Stein, D. J. (2000). Pathological gambling behaviour: emergence secondary to treatment of Parkinson's disease with dopaminergic agents. Depress. Anxiety 11, 185-186.

Sevy, S., Burdick, K. E., Visweswaraiah, H., Abdelmessih, S., Lukin, M., Yechiam, E., and Bechara, A. (2007). Iowa gambling task in schizophrenia: a review and new data in patients with schizophrenia and cooccurring cannabis use disorders. Schizophr. Res. 92, 74-84.

Sevy, S., Hassoun, Y., Bechara, A., Yechiam, E., Napolitano, B., Burdick, K., Delman, H., and Malhotra, A. (2006). Emotion-based decisionmaking in healthy subjects: shortterm effects of reducing dopamine levels. Psychopharmacology (Berl.) 188, 228-235.

Shinohara, K., Yanagisawa, A., Kagota, Y., Gomi, A., Nemoto, K., Moriya, E., Furusawa, E., Furuya, K., and Terasawa, K. (1999). Physiological changes in Pachinko players; beta-endorphin, catecholamines, immune system substances and heart rate. Appl. Human Sci. 18, $37-42$.

Shurman, B., Horan, W. P., and Nuechterlein, K. H. (2005). Schizophrenia patients demonstrate a distinctive pattern of decisionmaking impairment on the Iowa gambling task. Schizophr. Res. 72, 215-224.

Soubrie, P. (1986). Serotonergic neurons and behavior. J. Pharmacol. 17, 107-112.

St Onge, J. R., and Floresco, S. B. (2009a). Dopaminergic modulation of risk-based decision making.
Neuropsychopharmacology 34, 681-697.

St Onge, J. R., and Floresco, S. B. (2009b). Prefrontal cortical contribution to risk-based decision making. Cereb. Cortex 20, 1816-1828.

Starcke, K., Tuschen-Caffier, B., Markowitsch, H. J., and Brand, M. (2010). Dissociation of decisions in ambiguous and risky situations in obsessive-compulsive disorder. Psychiatry Res. 175, 114-120.

Stoltenberg, S. F., and Vandever, J. M. (2010). Gender moderates the association between 5-HTTLPR and decision-making under ambiguity but not under risk. Neuropharmacology $58,423-428$.

Suhr, J., and Hammers, D. (2010). Who fails the Iowa gambling test (IGT)? Personality, neuropsychological, and near-infrared spectroscopy findings in healthy young controls. Arch. Clin. Neuropsychol. 25, 293-302.

Suhr, J., and Tsanadis, J. (2007). Affect and personality correlates of the Iowa gambling task. Pers. Indiv. Dif. $43,27-36$.

Takahashi, Y. K., Roesch, M. R., Stalnaker, T. A., Haney, R. Z., Calu, D. J., Taylor, A. R., Burke, K. A., and Schoenbaum, G. (2009). The orbitofrontal cortex and ventral tegmental area are necessary for learning from unexpected outcomes. Neuron 62, 269-280.

Tchanturia, K., Liao, P. C., Uher, R., Lawrence, N., Treasure, J., and Campbell, I. C. (2007). An investigation of decision making in anorexia nervosa using the Iowa gambling task and skin conductance measurements. J. Int. Neuropsychol. Soc. 13 , 635-641.

Toplak, M. E., Jain, U., and Tannock, R. (2005). Executive and motivational processes in adolescents with attention-deficit-hyperactivity disorder (ADHD). Behav. Brain Funct. $1,8$.

Tucker, K. A., Potenza, M. N., Beauvais, J. E., Browndyke, J. N., Gottschalk, P. C., and Kosten, T. R. (2004). Perfusion abnormalities and decision making in cocaine dependence. Biol. Psychiatry 56, 527-530.

Uylings, H. B., Groenewegen, H. J., and Kolb, B. (2003). Do rats have a prefrontal cortex? Behav. Brain Res. 146, 3-17.

Uylings, H. B., and van Eden, C. G. (1990). Qualitative and quantitative comparison of the prefrontal cortex in rat and in primates, including humans. Prog. Brain Res. 85, $31-62$.

van den Bos, R., Den Heijer, E. Vlaar, S., and Houx, B. (2007).
"Exploring gender-differences in decision-making using the Iowa gambling task," in Psychology of Decision Making in Education, Behavior and High Risk Situations, ed. J. E. Elsworth (New York, NY: Nova Science Publications), 207-226.

van den Bos, R., Harteveld, M., and Stoop, H. (2009a). Stress and decision-making in humans: performance is related to cortisol reactivity, albeit differently in men and women. Psychoneuroendocrinology 34, 1449-1458.

van den Bos, R., Homberg, J., Gijsbers, E., Den Heijer, E., and Cuppen, E. (2009b). The effect of COMT Val158 Met genotype on decisionmaking and preliminary findings on its interaction with the 5-HTTLPR in healthy females. Neuropharmacology 56, 493-498.

van den Bos, R., Lasthuis, W., Den Heijer, E., Van Der Harst, J., and Spruijt, B. (2006). Toward a rodent model of the Iowa gambling task. Behav. Res. Methods 38, 470-478.

Verdejo-García, A., López-Torrecillas, F., Calandre, E. P., Delgado-Rodríguez, A., and Bechara, A. (2009). Executive function and decision-making in women with fibromyalgia. Arch. Clin. Neuropsychol. 24, 113-122.

Vertes, R. P. (2006). Interactions among the medial prefrontal cortex, hippocampus and midline thalamus in emotional and cognitive processing in the rat. Neuroscience 142, $1-20$

Weller, J. A., Levin, I. P., and Bechara, A. (2010). Do individual differences in Iowa gambling task performance predict adaptive decision making for risky gains and losses? J. Clin. Exp. Neuropsychol. 32, 141-150.

Whitlow, C. T., Liguori, A., Livengood, L. B., Hart, S. L., Mussat-Whitlow, B. J., Lamborn, C. M., Laurienti, P. J., and Porrino, L. J. (2004). Long-term heavy marijuana users make costly decisions on a gambling task. Drug Alcohol Depend. 76, 107-111.

Willner, P. (1995). Animal models of depression: validity and applications. Adv. Biochem. Psychopharmacol. 49, 19-41.

Yin, H. H., Ostlund, S. B., and Balleine, B. W. (2008). Rewardguided learning beyond dopamine in the nucleus accumbens: the integrative functions of cortico-basal ganglia networks. Eur. J. Neurosci. 28, 1437-1448.

Young, J. W., Van Enkhuizen, J., Winstanley, C. A., and Geyer, M. A. (2011). Increased risk-taking behaviour in dopamine transporter 
knockdown mice: further support for a mouse model of mania. J. Psychopharmacol. 25, 934-943.

Zack, M., and Poulos, C. X. (2007). A D2 antagonist enhances the rewarding and priming effects of a gambling episode in pathological gamblers. Neuropsychopharmacology 32, 1678-1686.

Zack, M., and Poulos, C. X. (2009). Effects of the atypical stimulant modafinil on a brief gambling episode in pathological gamblers with high vs. low impulsivity. J. Psychopharmacol. 23, 660-671.
Zeeb, F. D., Robbins, T. W., and Winstanley, C. A. (2009). Serotonergic and dopaminergic modulation of gambling behavior as assessed using a novel rat gambling task. Neuropsychopharmacology 34, 2329-2343.

Zeeb, F. D., and Winstanley, C. A. (2011). Lesions of the basolateral amygdala and orbitofrontal cortex differentially affect acquisition and performance of a rodent gambling task. J. Neurosci. 31, 2197-2204.

Conflict of Interest Statement: The authors declare that the research was conducted in the absence of any commercial or financial relationships that could be construed as a potential conflict of interest.

Received: 09 June 2011; paper pending published: 28 June 2011; accepted: 29 August 2011; published online: 10 October 2011.

Citation: de Visser L, Homberg JR, Mitsogiannis $M$, Zeeb FD, Rivalan $M$, Fitoussi A, Galhardo $V$, van den Bos $R$, Winstanley $C A$ and DelluHagedorn F (2011) Rodent versions of the Iowa gambling task: opportunities and challenges for the understanding of decision-making. Front. Neurosci. 5:109. doi: 10.3389/fnins.2011.00109

This article was submitted to Frontiers in Decision Neuroscience, a specialty of Frontiers in Neuroscience.

Copyright (c) 2011 de Visser, Homberg, Mitsogiannis, Zeeb, Rivalan, Fitoussi, Galhardo, van den Bos, Winstanley and Dellu-Hagedorn. This is an open-access article subject to a non-exclusive license between the authors and Frontiers Media SA, which permits use, distribution and reproduction in other forums, provided the original authors and source are credited and other Frontiers conditions are complied with. 